\title{
Magnitude and timing of density reduction are key for the resilience to severe drought in conifer-broadleaf mixed forests in Central Europe
}

\author{
Juan Carlos Zamora-Pereira ${ }^{1}$ (D) Rasoul Yousefpour $^{1}$ (D) Maxime Cailleret $^{2,3,4}$ (D) Harald Bugmann $^{3}$ (D) \\ Marc Hanewinkel ${ }^{1}$ (D)
}

Received: 16 April 2021 / Accepted: 1 July 2021 / Published online: 5 August 2021

(C) The Author(s) 2021

\begin{abstract}
- Key message We applied a modified forest gap model (ForClim) to depict changes in stand water transpiration via density reduction as a forest adaptation strategy. This approach is the key to analyzing the ecological resilience to drought, stressinduced mortality, and economic efficiency of managed mixed forest stands in Central Europe. The results show that specific geographic conditions and forest composition define the optimal stand density of drought-resilient forests.

- Context Reducing stand density has been recognized as a valid strategy to increase forest resilience to drought. Moreover, to develop adaptive management strategies (AMS) under climate change, it is crucial to consider not only drought resilience but also the economic efficiency of alternative AMS proposed to alleviate drought effects.

- Aims To analyze how decreased inter-tree competition among overstorey trees affects stand vulnerability to drought and its expected yield.

- Methods We integrated experimental thinning data and historical responses to drought years in a climate-sensitive forest gap model, ForClim. We tested a business as usual (BAU) and three alternative AMS ("do-nothing," low- and high-intensity overstorey removal) in mixed stands of Norway spruce (Picea abies), silver fir (Abies alba), and European beech (Fagus sylvatica) along an elevational gradient of 520-1020 m a.s.l. in Central Europe.

- Results High-intensity overstorey removal in mixed stands of all three species considerably increased forest volume growth resilience to drought and decreased stress-induced mortality by two-thirds vis à vis a "do-nothing" strategy. In sites including only conifer species, forest resilience was equally improved by high- and low-intensity overstorey removal compared to that in the BAU strategy. Regarding the timber economy, high-intensity overstorey removal resulted in a higher economic revenue of mixed stands ( $\sim 22 \%$ higher net present value than other strategies) on the high-elevation sites (> $1000 \mathrm{~m}$ a.s.l.).

- Conclusion Modifying forest density and structure by overstorey removal is principally suitable to increase forest resilience to drought and improve its economic efficiency. The magnitude of the effect however depends on the geographical setting and forest composition.
\end{abstract}

Contribution of the co-authors All the authors contributed to the study's conception and design. J.C.Z. performed material preparation, data simulation, and analysis. J.C.Z. wrote the first draft of the manuscript, and R.Y., M.C., H.B., and M.H. commented on previous versions of the manuscript. All the authors read and approved the final manuscript.

Handling Editor: Andreas Bolte

Juan Carlos Zamora-Pereira

juan.zamora@ife.uni-freiburg.de

Rasoul Yousefpour

rasoul.yousefpour@ife.uni-freiburg.de

Maxime Cailleret

maxime.cailleret@inrae.fr
Harald Bugmann

harald.bugmann@env.ethz.ch

Marc Hanewinkel

marc.hanewinkel@ife.uni-freiburg.de

Extended author information available on the last page of the article 
Keywords Adaptation to climate change $\cdot$ Net present value $\cdot$ Density reduction $\cdot$ Overstorey trees $\cdot$ Altitudinal gradient

\section{Introduction}

Droughts in combination with higher temperatures are a growing concern in terrestrial ecosystems, particularly for forests where drought-induced declines in tree growth and survival are reported. Climate change scenarios for Central Europe suggest an increase in the occurrence of consecutive dry days, as a function of the increase in temperature and decreases in precipitation and water availability (Greve et al. 2018; HoeghGuldberg et al. 2018). The negative impacts of drought on European temperate forests have increased in the past decades; particularly, rising temperatures and high seasonal variability in precipitation increase the likelihood of large-scale forest mortality (Neumann et al. 2017). Patterns of declining growth rates due to region-specific climate variability have been observed, and the limited species tolerance to hotter droughts impairs the capacity of individual trees and stands to recover from drought, thus increasing their mortality risk (Allen et al. 2015).

Drought stress caused by high evaporative demand and low soil water content affects whole-plant hydraulic conductance from the soil to the leaves (Bréda et al. 2006). Tree vulnerability to drought depends on its individual-, population-, and speciesspecific functional properties such as the stomatal regulation strategy or hydraulic architecture (Landsberg and Sands 2011; Martínez-Vilalta and Garcia-Forner 2017). Tree size plays an important role in the drought sensitivity of trees, usually with more detrimental impacts for taller trees (cf. Bennett et al. 2015). Stand characteristics (i.e., density, structure, composition) also interact with species vulnerability to shape forest response to drought (Forrester and Albrecht 2014). Importantly, tree species diversity can enhance forest resistance to drought (e.g., specific mixtures that improve water availability of forest stands; cf. Grossiord et al. 2014). However, factors such as the type of mixture and tree species identity, depending on site aridity, basal area, and age, greatly modulate the beneficial effects of mixtures regarding drought resilience, which thus cannot be generalized (Pardos et al. 2021).

Likewise, stand structure can modulate forest resilience to drought-induced growth declines, on the one hand by lower physiological vulnerability of understorey trees, and especially when small trees are released from competition (Jones et al. 2019). On the other hand, higher stand density often is linked to exacerbated growth reductions during drought due to the decreased availability of soil moisture (Gleason et al. 2017). Novel management strategies to increase the adaptive capacity of forest ecosystems are thus required. This will necessitate an improved understanding of the interactions between drought and management strategies, as the latter are affecting competition among trees for critical limiting resources.
Management can enhance the drought resilience of forests, i.e., their capacity to return to the level of functions observed prior to the event (e.g., growth rate). Through experimental density reduction across a range of forest types and sites, the role of density reduction for resilience in past droughts was investigated (e.g., Elkin et al. 2015; Sohn et al. 2016a), suggesting that in regions with a high probability of drought stress, short and intensive thinning intervals are useful to increase drought resilience. However, forest density reduction may not be appropriate in all conditions because it may increase soil evaporation in residual stands, and thus in turn induce drought stress (Bose et al. 2018; Gleason et al. 2017). Additionally, species-specific studies including a focus on the effects of tree size and the specific management approach are missing. Moreover, to develop adaptive management strategies in a climate change context, we need to consider not only drought resilience but also the economic efficiency of the management changes that are proposed to alleviate drought effects. For instance, a wide set of alternative management options and measures of forest resilience should be considered, depending on climate change impacts, benefits and costs expected from adaptation, and stakeholders' risk aversion (Yousefpour et al. 2017).

The use of climate-sensitive forest growth simulation models can support the development of new management strategies to increase forest resilience to drought (Fontes et al. 2010; Mäkelä et al. 2000). These models consider the species- and size-specific responses to changes in light and water availability in the stand, as well as local conditions that drive those responses (Mina et al. 2017a; Rasche et al. 2011). In landscapes experiencing drought, simulations of management intensity and harvesting types have been tested to evaluate the resilience of managed forests to climate change (e.g., Niinimäki et al. 2012; Seidl et al. 2017). Forest-enterprise, regional, and global assessments of adaptive management have also tested the effectiveness of forest growth simulation models to explore adaptive management options in decision-making (Thrippleton et al. 2020; Yousefpour et al. 2019; Yousefpour et al. 2018). Despite these recent applications of mechanistic simulation models for promoting forest resilience, only a few model applications consider both ecological (i.e., improving resilience to drought) and economic aspects.

Norway spruce (Picea abies (L.) Karst) and silver fir (Abies alba Mill.) are among the most widespread economically and ecologically important tree species in Europe. Monocultures of Norway spruce have shown less adaptability to changing climate conditions, especially to drought (Lévesque et al. 2013; Sidor et al. 2015), and vulnerability to subsequent disturbances (e.g., bark beetles; Temperli et al. 2013). In contrast, 
silver fir is characterized by a higher tolerance to drought (Zang et al. 2014). European beech (Fagus sylvatica L.) is the most abundant broadleaf forest tree in Central Europe (Dittmar et al. 2003) and is more drought-resistant than Norway spruce and silver fir (Niinemets and Valladares 2006; Zang et al. 2014). Although the three species can be found together in mixed mountain forests in Central Europe, their specific responses to mean annual temperature and the length of the growing season modify their performance along elevation gradients. At higher elevations, spruce is adapted well to the low prevailing temperatures, while at low elevations with high temperatures, fir and especially beech are adapted better (Kölling 2007). Accordingly, admixing silver fir and European beech is likely a good strategy to improve the resilience of Norway spruce stands in drought-prone environments.

Overstorey removal to improve the drought resilience in mountain mixed forests requires analyses that include species mixture as well as local to regional geographic conditions, e.g., topography, micro-climate, and soil formation (Lindner et al. 2010). Empirical and simulation studies analyzing the effects of contemporary and future climate change report different effects on tree growth and mortality, depending on the elevation and topography of mountain forests in Central Europe (Thrippleton et al. 2020). In the present study, we used historic drought resilience data from six managed sites along an elevational gradient (520-1020 m a.s.l. in southwestern Germany) to assess the effectiveness of overstorey removal for promoting drought resilience. Specifically, we simulated a "business as usual" (BAU) and a "do nothing" management strategy along with two adaptive strategies of high- and low-intensity overstorey removal. We applied the climatesensitive, process-based forest gap model ForClim that was modified to better capture the relationship between stand density (i.e., stand transpiration) and water availability on the one hand and the growth dynamics of these three species on the other hand. Moreover, we used simulated yield to calculate the economic efficiency of these strategies regarding timber production.

As the main objectives of this study, we investigated (1) how the magnitude and frequency of overstorey removals influenced the drought resilience of the stands; (2) how drought and stand composition interact with the resilience of forest growth; (3) how the geographical setting affects the optimal density of drought-resilient forests; (4) and how simulated management strategies affect the economic efficiency (net present value, NPV) of forests. The proposed approach allows for the short-term planning of thinning activities (i.e., over less than a decade) and, as a dynamic ecological-economic modeling system, provides the information necessary to adopt strategic changes in thinning over multiple decades.

\section{Methods}

\subsection{Study sites}

The data used for the simulation analysis and the design of the strategies came from experimental plots located at six sites in the Black Forest area, Southwest Germany (Figure 1). The management experiment included an irregular group shelterwood regeneration method ("Femelschlag"), comparing strategies with different regeneration phase lengths, and thus frequency of overstorey tree removal $(20,35$, and 50 years) and a control plot (removal of $50 \%$ of the 10 -year volumetric increment; Weise 1996). Plots of approximately 0.25 ha were established between 1980 and 1981 in 90- to 126-year-old stands dominated by Norway spruce and silver fir, in which no harvesting had taken place for the past 10 years (Puettmann et al. 2009). In every site, we chose an experimental control plot as the basis of our simulations ("business as usual" strategy; BAU). European beech covered 2 to $20 \%$ basal area of the sites 220, 222, 223, and 225 (Figure 1) in the first observation period (1980-1981). Each of the six sites differs in terms of geographical setting (e.g., parental material, topography, elevation), climate, and stand characteristics, leading to a wide range of light and water availability (Table 1). The expected mean annual increment (MAI) for spruce and fir monocultures varies between 7 and $6 \mathrm{~m}^{3} \mathrm{ha}^{-1}$ year ${ }^{-1}$ for low productivity sites and between 12.5 and $11 \mathrm{~m}^{3} \mathrm{ha}^{-1}$ year ${ }^{-1}$ for the medium productivity sites (Forrester et al. 2013). The climate is temperate, with mean annual temperature ranging from 8.3 to $5.5^{\circ} \mathrm{C}$ and annual precipitation ranging from 940 to $2020 \mathrm{~mm}$ along the elevational gradient between 520 and $1020 \mathrm{~m}$ a.s.l., respectively. Additional information about the sites and their management is provided in Weise (1996), Puettmann et al. (2009), and Forrester et al. (2013).

\subsection{The climate-sensitive forest gap model ForClim}

ForClim (v4.0.1.2) is a climate-sensitive forest gap model developed to simulate the dynamics of temperate forests over a wide range of environmental conditions, especially under varying management regimes and climate change scenarios (Bugmann 1996; Rasche et al. 2012). It has been successfully applied to predict species composition and productivity of temperate and mountain forests in Western Europe (Mina et al. 2017a; Rasche et al. 2012) and North America (Bugmann et al. 2001; Gutiérrez et al. 2016). The influence of climate and stand characteristics on demographic processes, i.e., tree growth, regeneration, and mortality, is based on specific ecological assumptions, simulated at the stand level.

The growth dynamics of every tree size cohort on small patches of land (here, $800 \mathrm{~m}^{2}$ ) are based on species-specific maximum growth rates, which are reduced depending on the extent to which environmental factors are at suboptimal levels 
Fig. 1 Location of the six study sites in the Black Forest (sites 221-223, 225), the SwabianFranconian Forest (site 224), and the South-Western Swabian Alps (site 220). For every site, species composition and elevation class (low, $<700 \mathrm{~m}$ a.s.l.; medium, $720-830 \mathrm{~m}$ a.s.l.; high, $>1000 \mathrm{~m}$ a.s.1.) are indicated

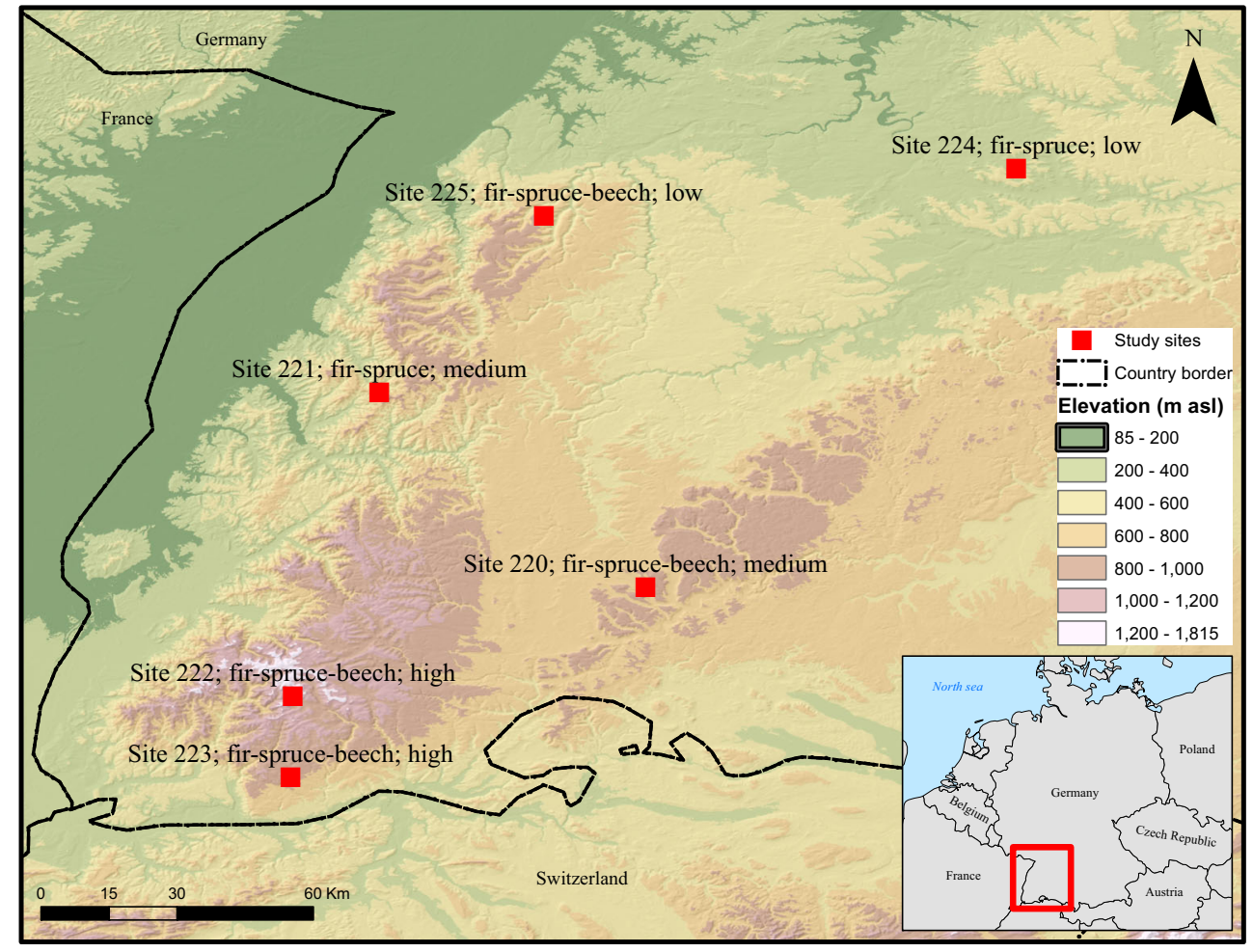

(Bugmann 2001; Moore 1989). Soil moisture, soil nitrogen, and degree days (sum of days with average temperature $>$ $5.5^{\circ} \mathrm{C}$ ) are site-specific growth reduction factors, whereas available light and crown length are growth reduction factors related to the development of the cohorts on each patch. Mortality of adult trees is determined based on a combination of a constant "background" mortality, which depends on the species-specific maximum age, and a stress-induced mortality that occurs if the annual stem diameter increment is lower than $0.3 \mathrm{~mm}$ or below $10 \%$ of the maximum specific diameter increment for three or more consecutive years (Bugmann 1996). Mortality is simulated individually for each tree within

Table 1 Geographical setting and stand characteristics

\begin{tabular}{|c|c|c|c|c|c|c|}
\hline & \multicolumn{6}{|l|}{ Study sites } \\
\hline & 220 & 221 & 222 & 223 & 224 & 225 \\
\hline Latitude/longitude & $\begin{array}{l}47^{\circ} 58^{\prime} \mathrm{N} / 8^{\circ} 53^{\prime} \\
\mathrm{E}\end{array}$ & $\begin{array}{l}48^{\circ} 26^{\prime} \mathrm{N} / 8^{\circ} 14^{\prime} \\
\mathrm{E}\end{array}$ & $\begin{array}{l}47^{\circ} 44^{\prime} \mathrm{N} / 7^{\circ} 58^{\prime} \\
\mathrm{E}\end{array}$ & $47^{\circ} 44^{\prime} \mathrm{N} / 8^{\circ} 1^{\prime} \mathrm{E}$ & $\begin{array}{l}48^{\circ} 56^{\prime} \mathrm{N} / 9^{\circ} 34^{\prime} \\
\quad \mathrm{E}\end{array}$ & $48^{\circ} 46^{\prime} \mathrm{N} / 8^{\circ} 26^{\prime} \mathrm{E}$ \\
\hline Elevation class (m a.s.1.) & Medium (830) & Medium (720) & High (1020) & High (1020) & Low $(520)$ & Low $(700)$ \\
\hline Parental material & Limestone & Sandstone & Gneiss & Granite & Sandstone & Sandstone \\
\hline Slope*, aspect & Flat & Steep, south & $\begin{array}{l}\text { Moderate, } \\
\text { south }\end{array}$ & $\begin{array}{l}\text { Moderate, } \\
\text { northeast }\end{array}$ & $\begin{array}{l}\text { Moderate, } \\
\text { south }\end{array}$ & $\begin{array}{l}\text { Moderate, } \\
\text { northwest }\end{array}$ \\
\hline Annual rainfall (mm; 1979-2016) & 944 & 1762 & 2022 & 1851 & 1151 & 1555 \\
\hline $\begin{array}{l}\text { Mean annual temperature } \\
\qquad\left({ }^{\circ} \mathrm{C} ; 1979-2016\right)\end{array}$ & 7.4 & 7.1 & 5.5 & 6 & 8.3 & 7.5 \\
\hline Average age (A. alba, P. abies) & 103,91 & 120,126 & 95,92 & 116,107 & 108,103 & 98,91 \\
\hline $\begin{array}{l}\text { Mean annual increment }\left(\mathrm{m}^{3}\right. \\
\left.\mathrm{ha}^{-1} \mathrm{yr}^{-1} ; \text { A. alba, P. abies }\right)\end{array}$ & $12.5,11$ & 7,6 & 12,10 & 7,10 & 11,9 & 11,10 \\
\hline Pre-treatment volume $\left(\mathrm{m}^{3} \mathrm{ha}^{-1}\right)$ & $598-707$ & $524-602$ & $460-580$ & $452-625$ & $468-656$ & $463-578$ \\
\hline $\begin{array}{l}\text { Species volume mixture }(\%) \text { at } \\
\text { installation; A. alba, N. spruce, } \\
\text { F. sylvatica }\end{array}$ & $79,17,4$ & $38,62,--$ & $60,24,16$ & $33,47,20$ & $42,58,--$ & $52,46,2$ \\
\hline
\end{tabular}

$*$ Classes of slope in the study sites: flat $=3^{\circ}$; moderate $=7^{\circ}$ to $14^{\circ}$; steep $=26^{\circ}$ 
a given cohort based on a stochastic approach using Monte Carlo techniques (more details in Bircher et al. 2015; Huber et al. 2020).

A flexible management submodel allows for the application of a broad range of common silvicultural treatments such as clear cutting, shelterwood, thinning, or planting (Rasche et al. 2011), and has been proven suitable to represent empirical and analytical harvesting algorithms like single-stem removal or relative diameter classes (Mina et al. 2017b). ForClim is a horizontally non-explicit forest model without interactions between individual simulated patches; hence, tree removals are executed randomly within the stand, but they depend on forest properties. In each patch, the harvesting algorithm selects trees to be removed based on their diameter at breast height (dbh) according to defined classes and rules until a certain volume is reached, using a stochastic Weibull function (Mina et al. 2017a; Rasche et al. 2011).

\subsection{Improvements in ForClim}

Despite several changes to the structure and parameterization of ForClim to better simulate tree growth and light environment (e.g., Huber et al. 2020; Mina et al. 2017b), the model tends to underestimate the growth release effect after a disturbance such as a management intervention (Didion et al. 2009). More importantly, the drought intensity experienced by each cohort in ForClim v4.0.1.2 is insensitive to stand density and does not change among stands subject to different management regimes. Elkin et al. (2015) improved the representation of water demand in the stand through an empirical relationship between evapotranspiration and leaf area index in the LandClim model. Yet, competition for water is still not simulated explicitly in ForClim (Huber et al. 2018). This had to be improved to accurately predict the effects of overstorey removal on forest resilience. Additionally, during extreme droughts, the growth reduction function in ForClim can reach zero, which rarely occurs in the field for these species and at these sites, while it strongly affects the calculations of resistance before and recovery after drought. This is due to the lack of a representation of carbon reserves in the model, which are used by trees to grow despite harsh conditions (Guillemot et al. 2017). Thus, beyond the age trend, the tree-level growth time series simulated by ForClim do not feature temporal autocorrelation (Bircher et al. 2015). Additionally, recent studies show an increase in mortality of trees with larger diameters, not only old trees, in European forests (Etzold et al. 2019; Senf et al. 2018). These issues were addressed by modifications to the model as described in Appendix 1.

\subsection{Identification of severe drought years}

We used the mean annual drought index (uDrAn) computed in ForClim to select and characterize drought years (details in
Bugmann and Cramer (1998) and Elkin et al. (2015)). The calculation of the drought index depends on the monthly ratio between evapotranspiration and the evaporative demand from the soil (sensu Eq. 5 in Appendix). Five drought years were identified, i.e., 1983, 1991, 2003, 2006, and 2016 (Appendix Fig. 9), with high values (uDrAn > 0.2) in the severe drought years 2003 and 2016, while the other drought years were mild $(\mathrm{uDrAn}<0.2)$.

\subsection{Measurement of resistance, recovery, and resilience}

To analyze the effects of overstorey removal strategies on forest growth resilience of the remaining individuals, we used an assessment of engineering resilience that is normalized by system state (Ingrisch and Bahn 2018). We framed the calculation of resilience and its components (Eqs. 1-3) by the indices developed by Lloret et al. (2011). Forest growth responses to drought were measured by mean annual volume increment (MAI; $\mathrm{m}^{3} \mathrm{ha}^{-1}$ year $^{-1}$ ) of the trees that were not harvested during the whole experiment, including new and advanced regeneration. MAI was calculated from the simulation results of dbh and height growth. The system state baseline for comparison was the pre- or post-disturbance growth rate (i.e., MAI), averaged over a 4-year period (cf. Anderegg et al. (2015) or DeSoto et al. (2020)):

Resistance $=$ Dr $/$ PreDr
Recovery $=$ PostDr $/ D r$
Resilience $=$ PostDr $/$ PreDr

where PreDr is the average MAI of the 4-year period preceding the drought, $D r$ is the MAI of the drought year, and Post $D r$ is the average MAI of the 4-year period following the drought. To analyze the temporal resilience of the remaining trees, we calculated the three indices for every year but focused our analysis on the identified drought years. For the drought year 1983, we used a baseline period of 2 years because the simulations start only in 1980-1981. In the case of the drought year 2016, we simulated the stand development until 2020 to compute the recovery and consequent resilience of the baseline of 4 years.

The use of growth based indices to quantify forest resilience has been criticized in the past because of the (a) inconsistency regarding the selection and characterization of drought events and (b) its calculation procedure (Schwarz et al. 2020). We consider that using the annual drought index in ForClim (cf. Subsection 2.4) is a consistent empirical process to select and characterize drought years. As for the second limitation, we agreed with the problems discussed; therefore, to corroborate our analysis of engineering resilience, we also 
analyzed the stress-induced mortality rate as an indicator of ecological resilience (Nikinmaa et al. 2020; Schwarz et al. 2020). To this end, we evaluated the mortality rate in a moving window of 4 years as the ratio between accumulated mortality (measured as $\mathrm{m}^{3}$ ) and total stand productivity at the end of the 4-year period (measured as $\mathrm{m}^{3}$ ).

\subsection{Adaptive forest management strategies considering an ecological-economic approach}

The ecological-economic effects of density reduction were simulated using a variable target diameter harvest of the initial overstorey trees (i.e., trees with $\mathrm{dbh} \geq 30 \mathrm{~cm}$ ). For this, we considered the greater sensitivity of taller trees to drought (Olson et al. 2018; Stovall et al. 2019) as well as the discounted net economic revenue for spruce-fir trees of the diameter classes $>40 \mathrm{~cm}$ (based on the regional averaged prices and costs for the period 2000-2016; see Appendix Table 5). We simulated the past BAU strategy for 36 years (1980-2016) along with three alternative management strategies, including two initial overstorey removal intensities and a "do nothing" strategy. Based on the frequency and intensity of the overstorey removal of the original experiment (Puettmann et al. 2009; Weise 1996), we simulated high- and lowintensity overstorey removal strategies. Under high intensity, the initial overstorey was removed over 20 years (1980-2000) in four harvesting intervals of 5 years (Table 2). The harvesting started with the more drought-vulnerable spruce trees with $\mathrm{dbh} \geq 60 \mathrm{~cm}$ (Sidor et al. 2015) and followed with silver fir and, when necessary, European beech (both $\geq 60 \mathrm{~cm}$ ). Once the initial trees in this class had been harvested, we continued in the same species order with trees between 40 and $60 \mathrm{~cm}$, and then between 30 and $40 \mathrm{~cm}$ until the initial overstorey was completely harvested. Afterwards, we applied control interventions (i.e., removal of $50 \%$ of the 10 -year volumetric increment) every 10 years. Under the low-intensity strategy, the entire overstorey would be removed over 50 years $(1980$ 2030). We applied control interventions every 10 years during 1980-2000 to foster the growth of overstorey trees. The first overstorey removal was applied in 2005 with an intensity of $20 \%$ of the current overstorey volume. We continued the lowintensity removal with $10 \%$ increases in the intensity rate every 5 years based on the overstorey volume measured in 2005 . We used the same dbh class and species order as in the highintensity strategy. Finally, under the "do nothing" strategy, we only applied a control intervention in the initial year (19801981) and continued the simulation without any management intervention. We used identical harvesting strategies for all sites.

\subsection{Model evaluation and application}

We evaluated the latest version of ForClim (v.4.0.1.2, as described in Appendix 1) against forest inventory data from the original experimental plots. For each site, forest dynamics were simulated under BAU, "do nothing," and the two adaptive management strategies. Climatic conditions were based on regionalized station-based data of precipitation and air temperature with a monthly resolution (German Weather Service; Dietrich et al. 2019). The stands were initialized using dbh data from the forest inventory conducted between 1980 and 1981. Each tree was randomly allocated to the ForClim patches, whose number was obtained by dividing the original site area by the patch size of $800 \mathrm{~m}^{2}$. To reduce stochastic noise in the simulations (Didion et al. 2009), individual patches were replicated 200 times. Tree regeneration was allowed to occur naturally in every simulation constrained by site conditions and browsing pressure (Appendix Table 4). From the outcomes of the model at the patch level, we upscaled the values to 1 hectare (i.e., basal area, standing volume, and stress-induced mortality). To evaluate the goodness-of-fit between BAU inventory observations and
Table 2 Frequency and intensity of the harvest interventions (BAU in reality and three alternative strategies) in the simulations

\begin{tabular}{|c|c|c|c|c|}
\hline \multirow[t]{2}{*}{ Year } & \multicolumn{2}{|l|}{ Adaptive management strategy } & \multirow{2}{*}{$\begin{array}{l}\text { BAU (business } \\
\text { as usual) }\end{array}$} & \multirow{2}{*}{$\begin{array}{l}\text { "Do } \\
\text { nothing" }\end{array}$} \\
\hline & $\begin{array}{l}\text { Low-intensity initial overstorey } \\
\text { removal (Low) }\end{array}$ & $\begin{array}{l}\text { High-intensity initial overstorey } \\
\text { removal (High) }\end{array}$ & & \\
\hline 1980 & Control* & Control & Control & Control \\
\hline 1985 & --- & $35 \%$ overstorey & --- & --- \\
\hline 1990 & Control & $50 \%$ overstorey & Control & --- \\
\hline 1995 & --- & $85 \%$ overstorey & --- & --- \\
\hline 2000 & Control & $100 \%$ overstorey & Control & --- \\
\hline 2005 & $20 \%$ overstorey & --- & --- & --- \\
\hline 2010 & $30 \%$ overstorey & Control & Control & --- \\
\hline 2015 & $40 \%$ overstorey & --- & --- & --- \\
\hline
\end{tabular}

*Removal of $50 \%$ of the 10 -year volume increment for trees with a $\mathrm{dbh} \geq 10 \mathrm{~cm}$ 
simulations, we used the relative root mean square error (RMSE) and the percent bias (pbias).

We simulated the four forest management strategies in every site and analyzed the results of the resistance, recovery, resilience, and stress-induced mortality rates for each strategy. We looked for their differences during the observation period and identified drought years, considering all six sites individually and their forest composition (fir-spruce and fir-sprucebeech) and elevation (low, medium, and high). We evaluated pairwise differences among management strategies $(t$-test for paired samples). To analyze the economic implications of the four management strategies, we calculated the expected economic benefits in terms of net present value (NPV), estimating the cash flow of harvest interventions and the corresponding changes in stumpage value. Based on the aims of our study and expected low aversion to risk of the forest managers of our research area, we used a discount rate of $1 \%$ (Yousefpour et al. 2017). Averaged prices and costs by diameter classes for Baden-Württemberg for the period 2000-2016 (see Appendix Table 5) are used in the calculation of NPV:

$N P V=\sum_{t=0}^{n} \frac{R_{t}}{(1+i)^{t}}$

where $R_{\mathrm{t}}$ is the net cash inflow-outflow during a single period $t, i$ is the discount rate, and $n$ is the number of periods. All calculations and analyses were performed in the R environment ( $\mathrm{R}$ 3.5.3; Development Core Team R 2019).

\section{Results}

\subsection{Model evaluation}

ForClim simulations of basal area (BA) and standing volume matched the observed data over 36 years (eight inventories from 1980 to 2016) quite well, with a percentage bias $<2 \%$ and $<5 \%$, respectively. As Figure 2 shows, in fir-spruce mixed sites, simulations of BA marginally underestimated the observed values, ranging from -1.9 to $-0.8 \%$. There were negligible underestimation and overestimation of BA in sites where European beech is present, ranging from -0.6 to $+1.5 \%$. Standing volume showed a slightly higher bias $(-4.7$ to $+0.6 \%)$ compared to BA (Appendix Fig. 10). Results of the relative RMSE of BA and standing volume showed similar patterns of differences among sites. Overall, ForClim simulated stand development under current management and climate conditions very well (additional information is provided in Appendix 2).

\subsection{Model application}

The intra-site comparison among overstorey removal strategies indicated that volume MAI (i.e., forest growth) diverged between the strategies along the simulation period (Figure 3). During the first 20 years, the high-intensity overstorey removal showed the lowest volume MAI at all sites, while the rest of the strategies (i.e., low-intensity, BAU, and "do nothing") maintained forests with nearly complete stock and similar high MAI values. However, in 2009, 1 year before a control intervention and almost a decade after the complete initial overstorey removal under the high-intensity treatment, MAI increased in all sites by $\sim 0.7 \mathrm{~m}^{3} \mathrm{ha}^{-1}$ year ${ }^{-1}$. During the first two decades of the experiment, the low-intensity removal strategy showed a positive but decreasing trend in MAI, by $\sim 0.68 \mathrm{~m}^{3} \mathrm{ha}^{-1}$ year ${ }^{-1}$ and $\sim 0.42 \mathrm{~m}^{3} \mathrm{ha}^{-1}$ year $^{-1}$, respectively. After 2005, MAI decreased by $\sim-4.7 \mathrm{~m}^{3} \mathrm{ha}^{-1}$ year ${ }^{-1}$ over 10 years, as more overstorey trees were removed. At the highelevation sites, the MAI of the high-intensity strategy exceeded that of the low-intensity strategy by the end of the simulation, with increases of $+1.4 \mathrm{~m}^{3} \mathrm{ha}^{-1}$ year $^{-1}$ at site 222 and $+2.4 \mathrm{~m}^{3} \mathrm{ha}^{-1}$ year $^{-1}$ at site 223 . Overall, MAI was positively affected by standing volume and tree size but negatively affected by the intensity and timing of overstorey removal.

Forest growth responses to overstorey removal during drought years differed by species composition and the geographical setting. High-elevation stands (sites 222 and 223) with moderate slope $\left(>12^{\circ}\right)$ and higher soil water holding capacity ("bucket size," BS $=20 \mathrm{~cm}$ ) showed a higher volume MAI under the high-intensity overstorey removal. Hence, no drought-induced negative effect on growth rates was detectable at these sites under the high-intensity strategy $(\sim+12 \%$ higher MAI during the severe drought of 2003; Figure 3). Sites below $1000 \mathrm{~m}$ a.s.l., however, showed an increased sensitivity to drought events under all strategies (e.g., decrease of MAI in 2003). The volume MAI showed an entirely different magnitude of effect in fir-spruce-beech sites under the highintensity strategy, depending on its elevation, slope, and BS. In site 220 , located at $830 \mathrm{~m}$ a.s.l. with a gentle slope $\left(3^{\circ}\right)$ and BS of $20 \mathrm{~cm}, \mathrm{MAI}$ increased by $+4.4 \%$ during the drought of 2003. In site 225 , located at $700 \mathrm{~m}$ a.s.l. with a moderate slope $\left(14^{\circ}\right)$ and BS of $14 \mathrm{~cm}$, volume MAI decreased by $-7.7 \%$. For the same overstorey removal strategy in fir-spruce sites, MAI decreased by $\sim-38 \%$. Site 224 , located at $520 \mathrm{~m}$ a.s.l. with a moderate slope and BS of $14 \mathrm{~cm}$, showed the greatest decrease in volume MAI by $-66.5 \%$. Site 221 , at $720 \mathrm{~m}$ a.s.l. with a steep-south slope of $26^{\circ}$ and BS of $12 \mathrm{~cm}$, showed a decrease of $-9.3 \%$ during the drought year 2003 .

Under the low-intensity strategy, across the entire elevational gradient, MAI decreased by $\sim-14 \%$ in sites with three species and by $\sim-70 \%$ in sites with a fir-spruce composition. Lower elevation $(<1000 \mathrm{~m}$ a.s.l.) and smaller bucket size $(<14 \mathrm{~cm})$ affected negatively the volume MAI. For the 
Fig. 2 Simulated basal area $\left(\mathrm{m}^{2}\right.$ $\mathrm{ha}^{-1}$ ) under business as usual (BAU) strategy: control interventions (removal of $50 \%$ of the 10 -year volume increment for trees $\geq 10 \mathrm{~cm}$ in dbh). Black circles represent the measured values in the inventory every 5 years. Circles in 1979, for sites 220-223, and 1980, for sites 224 225 , represent the model initialization values. Values in the labels indicate measures for goodness-of-fit including all the inventory measurements
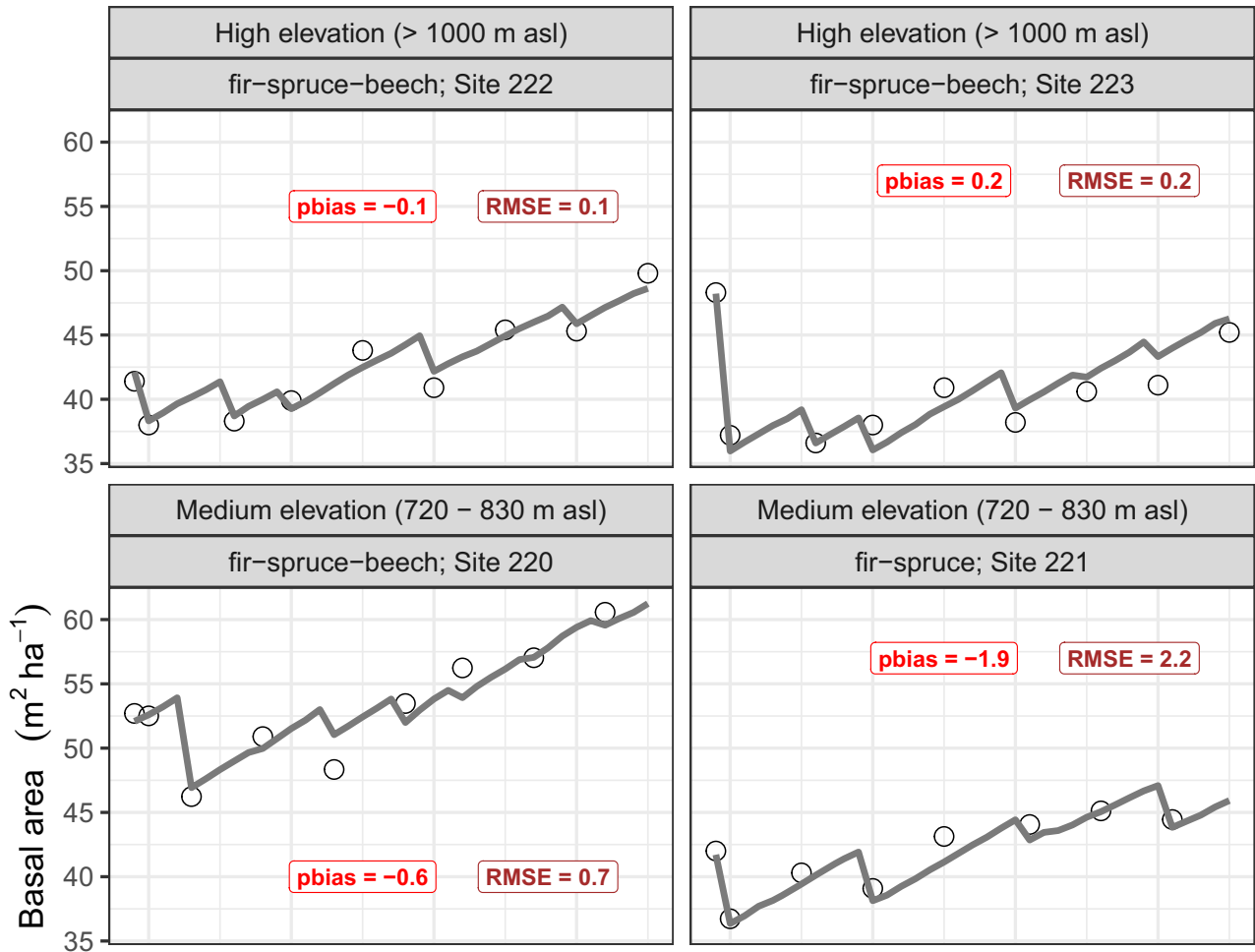

Medium elevation $(720-830 \mathrm{~m}$ asl)

fir-spruce; Site 221
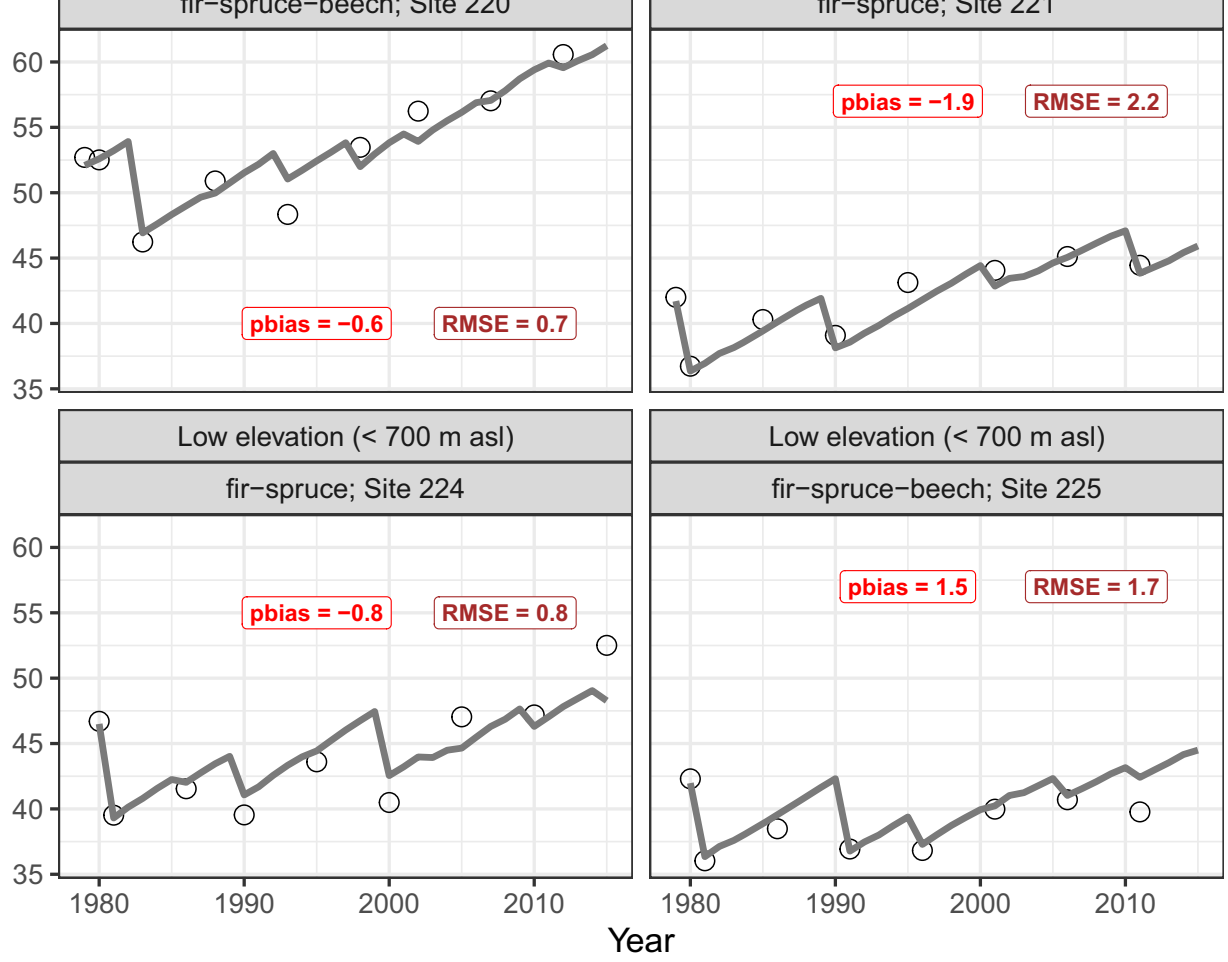

Inventory

Simulation ForClim

a pbias (\%) a RMSE (\%)
BAU and "do nothing" strategies, the 2003 severe drought reduced volume MAI by $\sim-15 \%$ and $\sim-70 \%$ in sites with three and two species, respectively. Overall, across the complete elevation gradient, high-intensity overstorey removal decreased the drought effect on volume MAI, with a higher magnitude in stands including European beech and higher water availability.

\subsection{Forest resilience, resistance, and recovery}

\subsubsection{Resilience, resistance, recovery, and management strategies}

We analyzed forest resilience, resistance, and recovery from drought of the trees remaining after management interventions. The stands under the "do nothing" and BAU strategies behaved similarly, but we found differences between these and stands under both the low- and highintensity strategies (Figure 4). Analyzing the five drought years, high-intensity overstorey removal had the highest average growth resilience $(\sim 1.05)$ and resistance $(\sim 0.93)$ among all strategies. It also was the lowest-performing strategy in terms of growth recovery $(\sim 1.29)$, but it was still larger than 1.0 , indicating the capacity of stand growth to recover following drought events. The magnitude of the effects in terms of resilience and resistance to drought among the other management strategies decreased with increasing presence of overstorey trees and total stand volume. Consequently, stand performance in terms of resilience and resistance declined progressively under the low-intensity overstorey 
Fig. 3 Simulated mean annual increment (MAI) under the four management strategies including BAU, low- and high-intensity overstorey removal, and a do nothing strategy (see details in Table 2). Gray vertical lines indicate drought years (1983, 1991, 2003, 2006, and 2016)

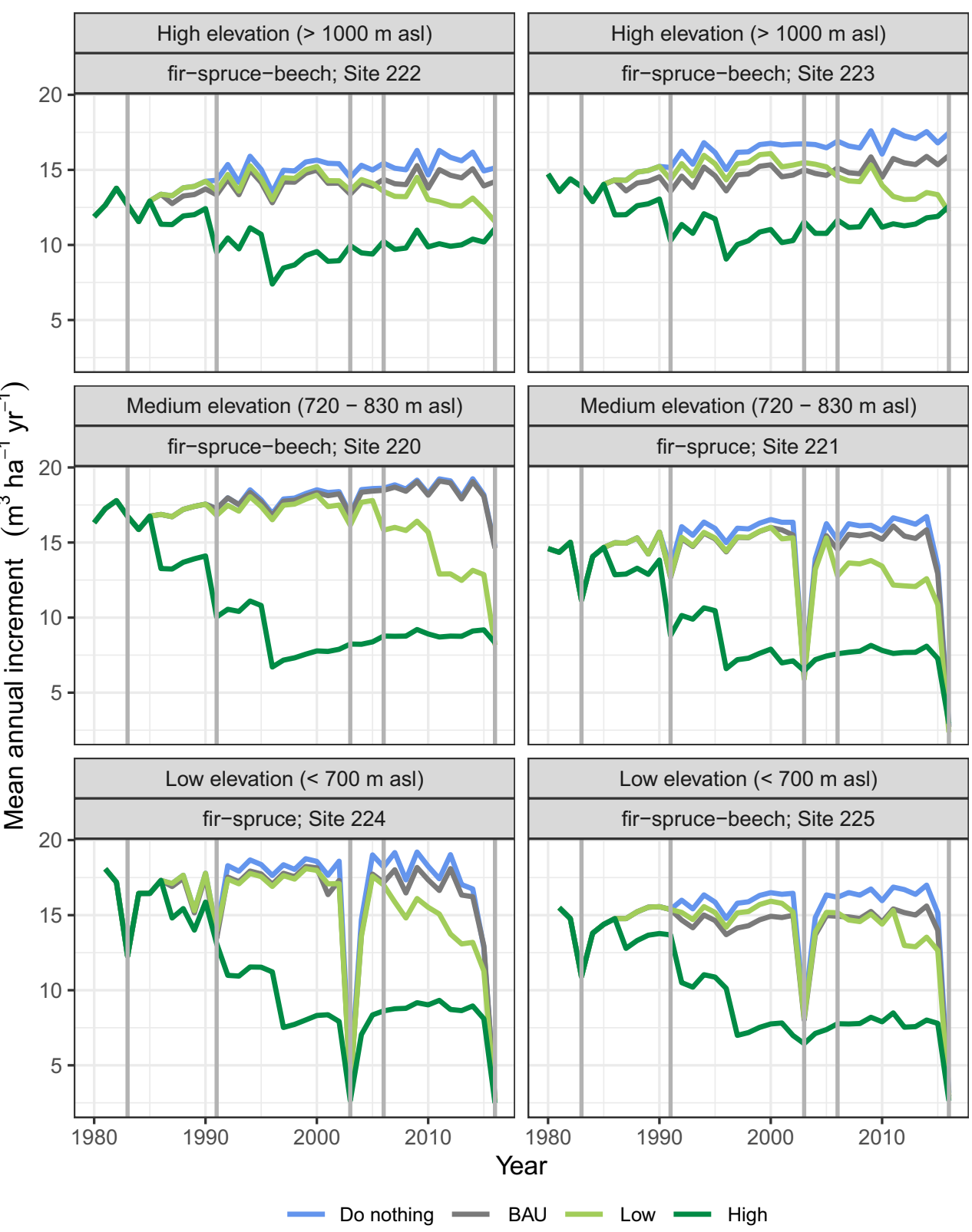

removal, BAU, and "do nothing" strategies, respectively. The inverse order of strategies described the progressive decline in stand performance regarding recovery. Overall, during drought years, forest resilience and resistance were low under strategies maintaining a higher standing volume and more overstorey trees, whereas these strategies showed higher recovery.

When overstorey removal occurred just before or after a drought year ( \pm 4 years), forest resilience increased compared to the control interventions of BAU. Specifically, during the droughts of 1983, 1991, and 2003, high-intensity overstorey removal induced the highest resistance to drought $(\sim+1 \%, \sim$ $+7 \%$, and $\sim+25 \%$, respectively). Due to these increases of resistance, forest resilience was also highest during the droughts of $1991(\sim+9.5 \%)$ and $2003(\sim+7 \%)$. Meanwhile, during the 2006 drought, low-intensity overstorey removal showed the highest resilience $(\sim+6 \%)$, resistance $(\sim+5 \%)$, and recovery $(\sim+1 \%)$ values compared to the other strategies. Finally, in the drought of 2016, only the growth rate under the low-intensity strategy was resilient to drought $(\sim 1.01)$ due to increased resistance $(\sim+8 \%)$ and recovery $(\sim+1 \%)$ relative to the other strategies. The remaining strategies with control interventions showed resilience lower than 1 , indicating that the previous growth rate was not recovered in the 4 years following the drought. Thus, compared to control interventions, the application of overstorey removal interventions positively affects the resilience (mostly by increasing forest resistance to droughts; see details in Appendix Figs. 11 and 12). 
Fig. 4 Differences in forest resilience of remaining trees among four management strategies during drought years. Forest resilience was calculated using the average MAI of living trees during 4 years pre- and postdrought as system state baseline. To calculate the resilience to the drought of 1983, we used 2 years as baseline, and for the drought of 2016 , the model was allowed to run until 2020
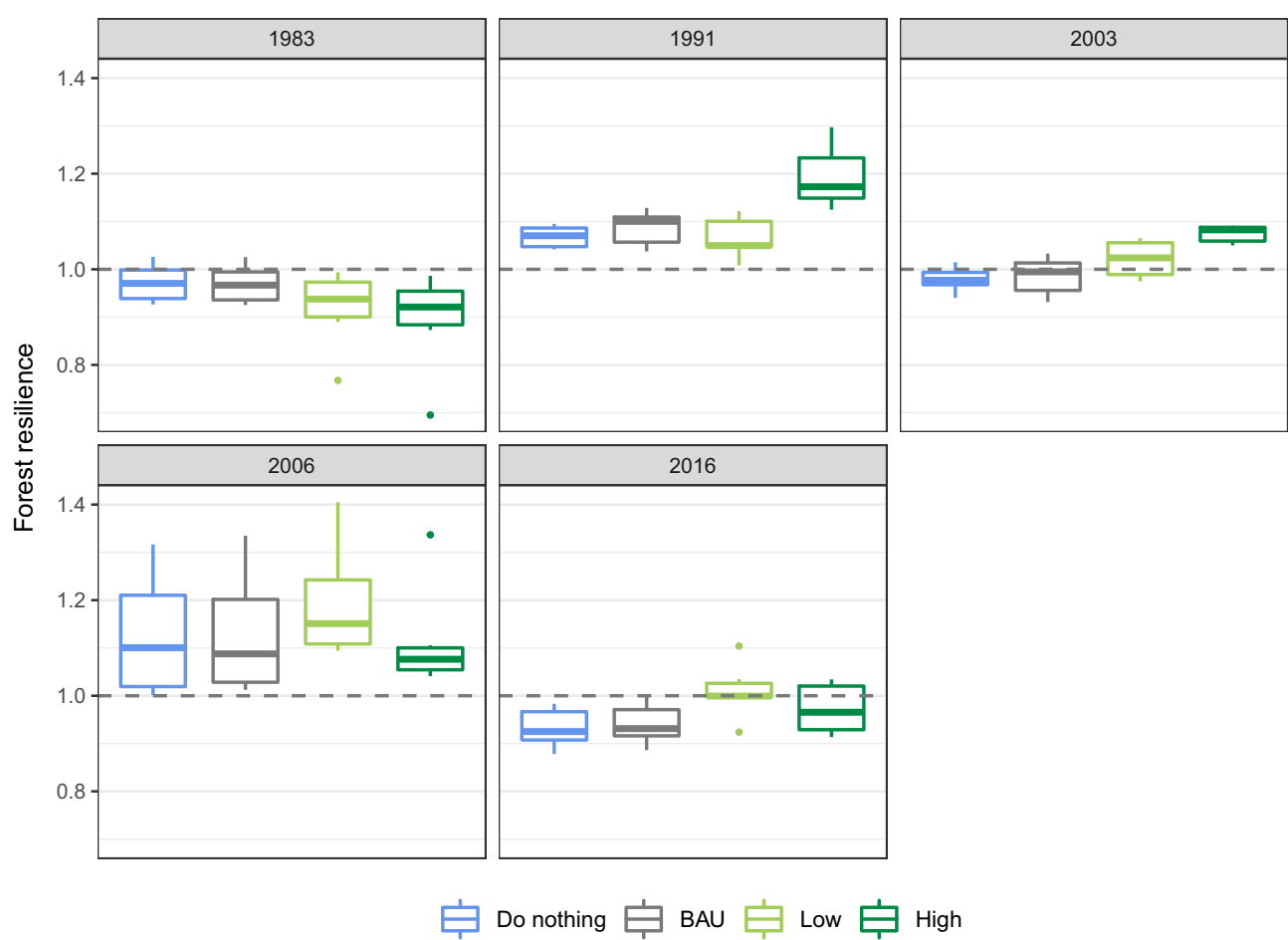

\subsubsection{Resilience, resistance, recovery, and forest composition}

In the analysis of forest resilience under management strategies by drought year, we observed a different pattern for the two site groups with different forest compositions (i.e., firspruce vs. fir-spruce-beech). During the first decade of the experiment, both types of stand composition showed an increasing trend in forest resilience under all strategies $(\sim+17 \%$ in fir-spruce-beech and $\sim+10 \%$ in fir-spruce), while in both cases, the magnitude of the effect was higher under the high- intensity overstorey removal (Figure 5). After the drought of 1991, the decreasing trend in resilience under all strategies ( $-9 \%$ ) was reversed only slightly in fir-spruce-beech stands, while the stands with fir-spruce composition showed a continuously decreasing trend $(\sim-36 \%, \sim-42 \%, \sim-32 \%,-22 \%$ under the "do nothing," BAU, low-intensity, and highintensity overstorey removal strategies, respectively). Throughout the two consecutive droughts in 2003 and 2006, the decreasing trend was reversed in fir-spruce stands under all strategies $(\sim+38 \%, \sim+40, \sim+40 \%, \sim+21 \%$ under "do
Fig. 5 Forest resilience to drought by forest composition and management strategy. The values by management strategy are averaged over stands composed of fir-spruce-beech and fir-spruce trees. Gray vertical lines indicate drought years (1983, 1991, 2003, 2006, and 2016)

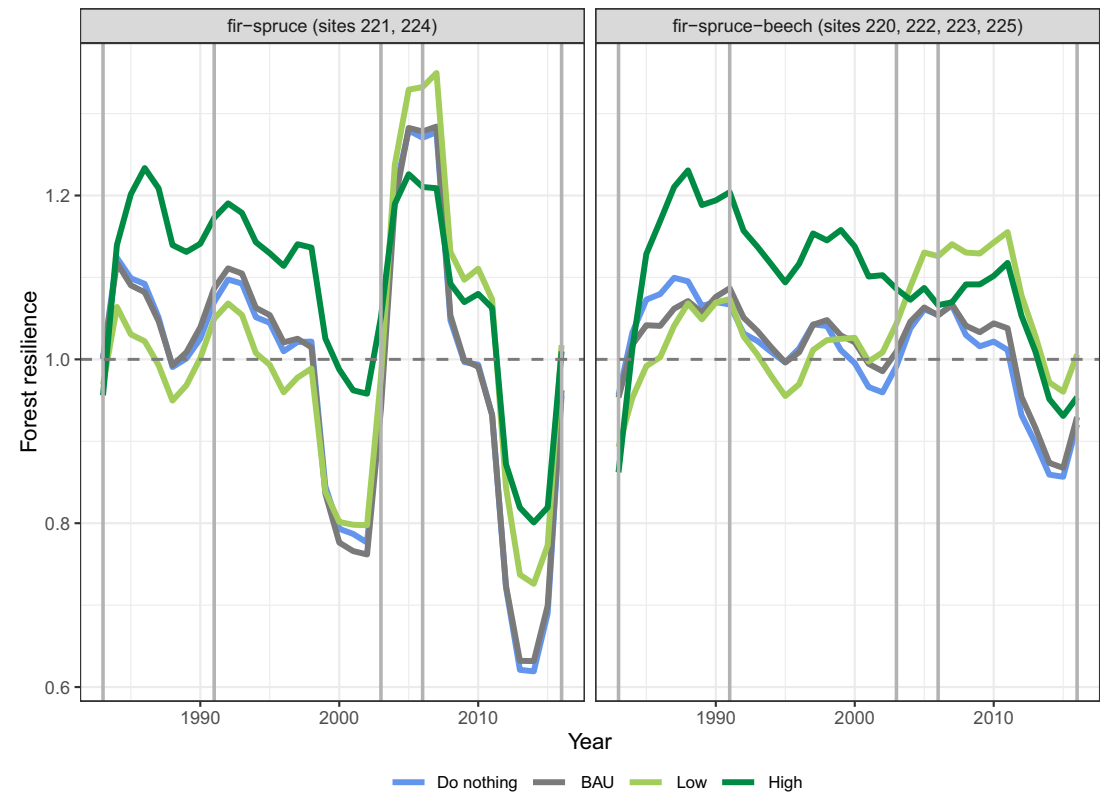


nothing," BAU, low-intensity, and high-intensity overstorey removal strategies, respectively). During the same period, the magnitude of the effect was smaller in fir-spruce-beech stands under all strategies $(\sim+6 \%)$. Finally, between the last two droughts (2006-2016), forest resilience decreased in both stand composition types, but to a lower extent in fir-sprucebeech stands $(\sim-13 \%)$, while in fir-spruce stands, the effect was higher, especially under the "do nothing" and BAU strategies $(\sim-33 \%)$. On average across the whole period, the resilience of fir-spruce-beech stands was higher than that of firspruce stands.

The effect of management strategies on forest resistance and recovery of the two site groups also depended on drought severity. In particular, in fir-spruce stands under all strategies, the effects of the severe droughts in 2003 and 2016 decreased on average its resistance by $\sim-67.5 \%$ (Appendix Fig. 13). This decrease was compensated by an increase in recovery in the next 4 years $(\sim+364 \%$; Appendix Fig. 14$)$. During the mild droughts of 1983, 1991, and 2006, its resistance and recovery followed the same pattern but to a lower extent $(\sim-9.6 \%$ and $\sim 14.1 \%$, respectively). For fir-spruce-beech stands, during severe droughts, the decrease in resistance was smaller than in the other site group $(\sim-14.1 \%)$, while its recovery showed an inverse response, being higher than the decrease in resistance $(\sim+65.1 \%)$. During the mild droughts, the increase in forest resistance was counteracted by a decrease in recovery $(\sim+3.1 \%$ and $\sim-3 \%$, respectively). Overall, severe droughts had a larger effect on resistance and recovery than mild droughts. In addition, the presence of European beech in the mixture favored a high and more stable resistance and recovery.

\subsection{Mortality}

The stress-induced mortality rate decreased depending on the intensity of forest management, with reduced mortality under higher overstorey removal strategies, especially compared to the "do nothing" strategy. The average reduction of the mortality rate during the experiment (1980-2016) was highest under high- and low-intensity overstorey removal $(\sim-57.3 \%$ and $\sim-61.7 \%)$. Under BAU, the reduction was considerably lower ( $-21.1 \%)$, while under the "do nothing" strategy, the mortality rate increased slightly $(\sim+5.8 \%$; Figure 6$)$. Under the overstorey removal strategies, high-intensity overstorey removal every 5 years resulted in a decrease of the mortality rate of $\sim-66.7 \%$ between 1980 and 2000 . For the same stands, the mortality rate increased $(\sim+28 \%)$ when a control intervention was executed only every 10 years in the period 2001-2016. The stands with low-intensity overstorey removal showed a decreased mortality rate $(\sim-19 \%)$ for the period 1980-2000 when control interventions were applied. In 2001-2016, when overstorey removal started under the lowintensity management, the mortality rate decreased by $-52.7 \%$. Overall, the magnitude of the effect in the reduction of the mortality rate depended on the type and timing of the management intervention.

The mean dbh of dead trees decreased over the simulation period under the "do nothing" strategy, varying by elevation. Higher stress-induced mortality in trees with a dbh $<25 \mathrm{~cm}$ was found at low and medium elevations, with a mean dbh of living trees of $39 \mathrm{~cm}$ and $37 \mathrm{~cm}$, respectively. At high elevations, the mean dbh of living trees was $35 \mathrm{~cm}$, and trees with a $\mathrm{dbh}<20 \mathrm{~cm}$ were most affected by the increased stressinduced mortality rate (Appendix Fig. 15). Altogether, these responses indicate a high sensitivity of the stress-induced mortality rate to the timing and magnitude of overstorey removal. Thus, following a "do nothing" strategy in the face of increasing drought impacts on forests is likely to result in higher mortality, especially among understorey trees.

\subsection{Economic assessment}

Net present value (NPV) was affected by the overstorey removal strategies. Compared to BAU, NPV increased with increasing overstorey removal intensity and frequency. In high-elevation fir-spruce-beech stands (sites 222 and 223), the high-intensity removal performed best, with an average $\sim+22 \%$ increase in NPV from 1980 to 2016 (Figure 7). Medium- and low-elevation stands composed of three species showed similar results. At the medium-elevation stand (site 220 ), the high-intensity strategy resulted in a $+49 \%$ higher NPV than the BAU strategy. At the low-elevation stand (site 225 ), the high-intensity strategy showed a $+10 \%$ higher NPV. Fir-spruce stands at medium and low elevation resulted in a higher NPV under the high-intensity strategy than BAU, but the difference was smaller than that of fir-spruce-beech sites. At sites 221 and 224, the average expected value of the stand was $\sim+3.7 \%$ higher under the high-intensity strategy. Overall, in stands with three species, NPV under the BAU scenario was lower than NPV under either overstorey removal strategy but still higher than that under the "do nothing" management. In fir-spruce sites, the NPV of BAU was slightly lower than that of the overstorey removal strategies but higher than under the "do nothing" management.

\section{Discussion}

Our results show a strong positive effect of overstorey removal strategies on forest resilience to drought. In contrast, a "do nothing" strategy is likely to increase tree mortality, particularly for understorey trees. Our simulations also indicate differences related to the geographical setting and stand composition, with high resilience in forest stands at low- and medium-elevation sites. However, the economic output of high-intensity strategies on high-elevation sites was higher than that under other strategies. 
Fig. 6 Stress-induced mortality rate among management strategies. Gray vertical lines indicate drought years (1983, 1991, 2003, 2006, and 2016)
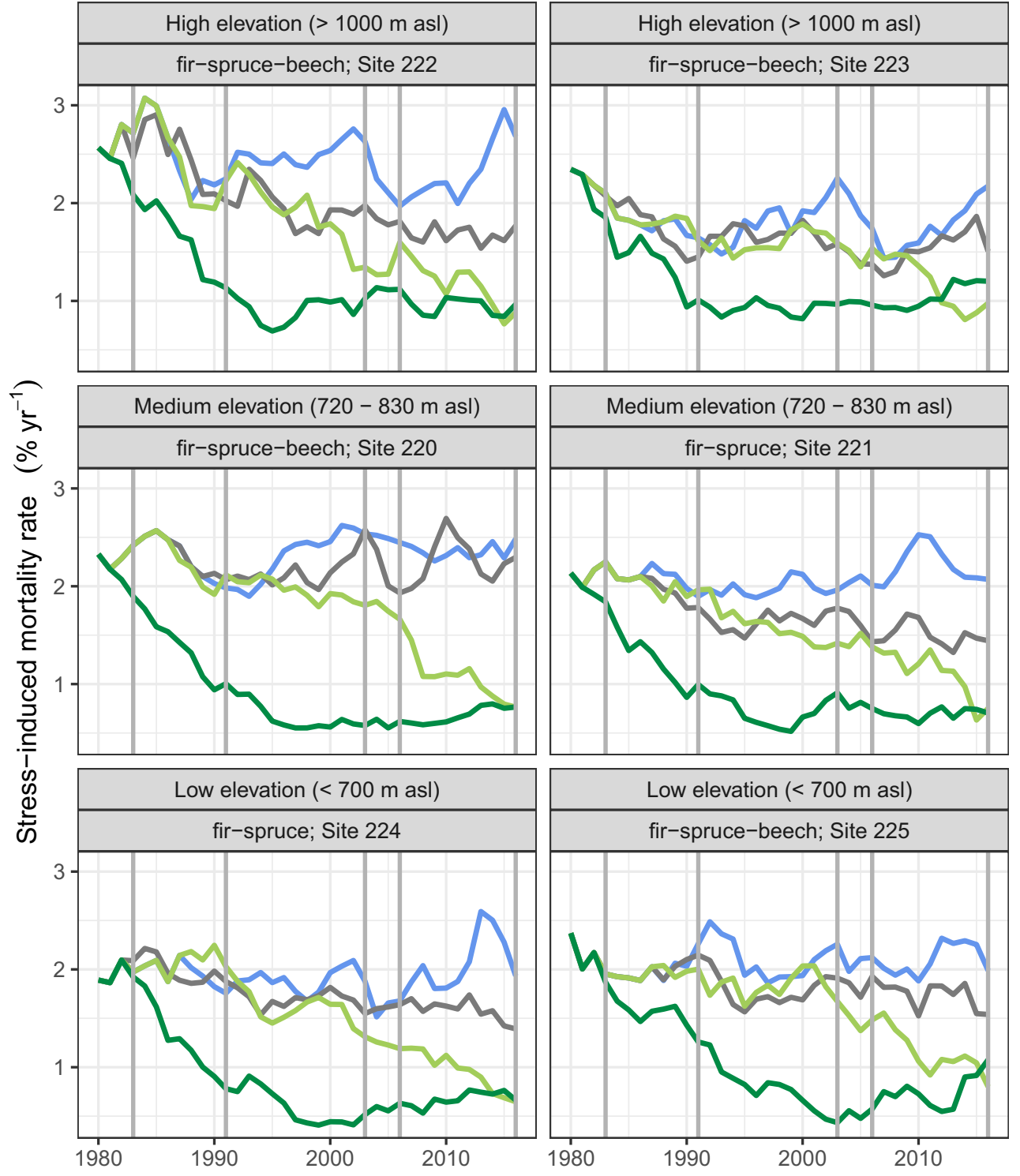

Year

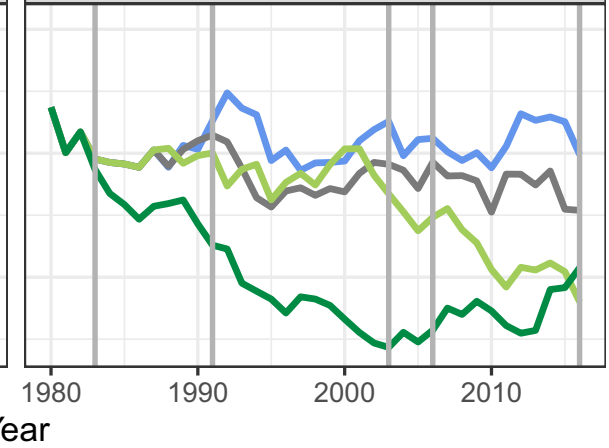

Do nothing $\longrightarrow$ BAU Low High

\subsection{Forest structure and forest resilience}

We found that a high frequency and high intensity in overstorey removals promoted forest resilience following drought events, confirming the results of Puettmann et al. (2009) who evaluated empirical indices in the same study sites and explained this increase in resilience as a consequence of release effects following density reduction. In contrast to the simulations under the "do nothing" and BAU management strategies, the gaps produced by the overstorey removal strategies positively influenced the growth of new regeneration or otherwise suppressed young trees ("advanced regeneration"; Jones et al. 2009).

The magnitude of the growth response to thinning strategies is likely to vary with tree size and light-use efficiency. For example, light absorption and light-use efficiency are strongly influenced by the structure and composition of individual trees' neighborhoods along this elevation gradient (Forrester and Albrecht 2014). Thus, by starting the harvesting with taller trees, adaptive management strategies allow for the growth of shade-tolerant silver fir trees that tolerate dense neighborhoods dominated by Norway spruce (Forrester et al. 2013). Furthermore, the harvest of taller trees increased the light share for young trees, which reduced its stress-induced mortality in combination with greater soil resource availability (Berntson and Wayne 2000). Moreover, the growth and survival of previously suppressed trees benefited from overstorey removal in short intervals (i.e., 5-10 years; cf. Elkin et al. 2015; Sohn et al. 2016b). 
Fig. 7 Net present value (NPV) of the stands using $1 \%$ as the discount rate. Gray vertical lines indicate drought years (1983, 1991, 2003, 2006, and 2016)
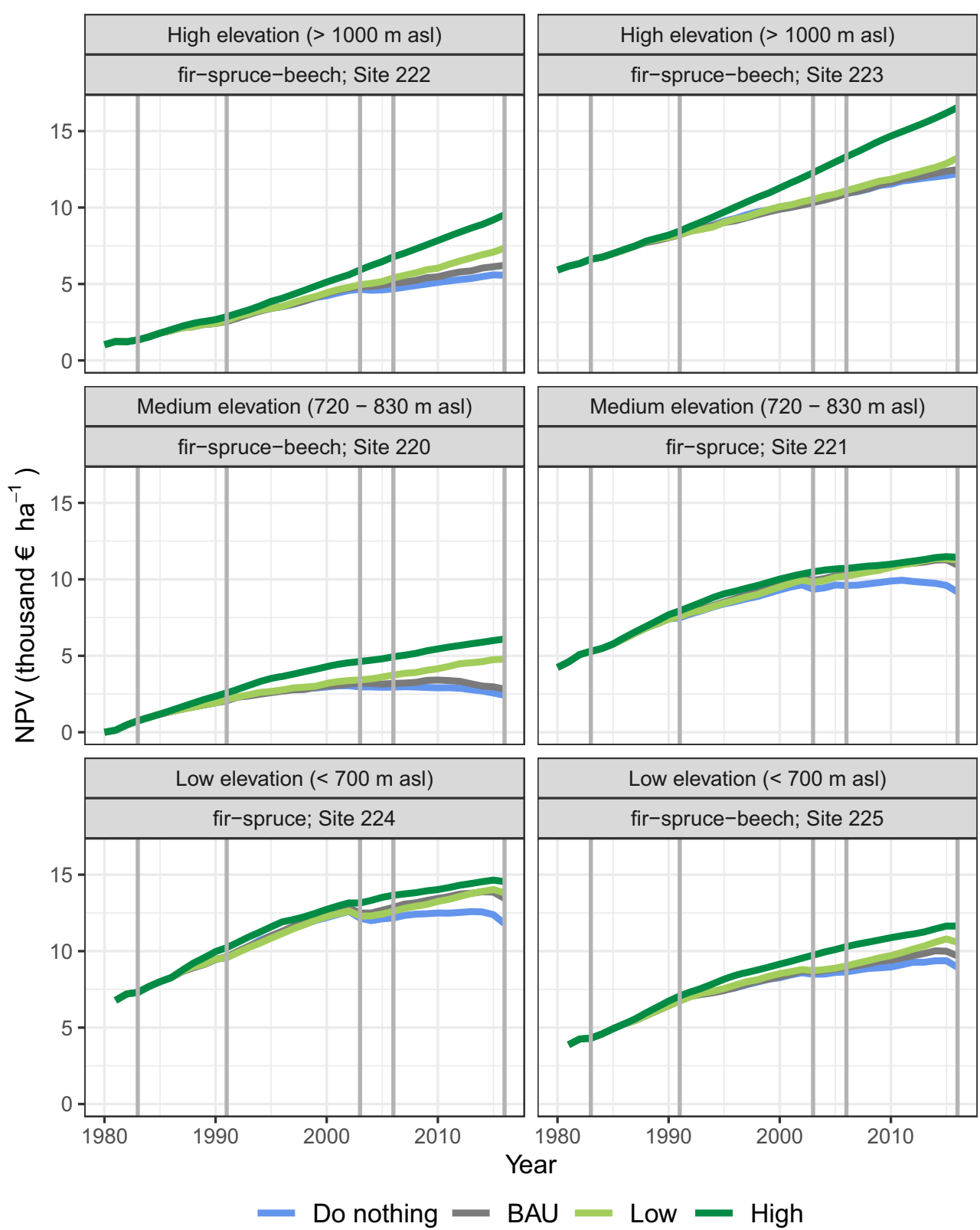

Forest resilience to drought was also enhanced by improved water availability, driven by the decreased inter-tree competition among overstorey removal strategies in coniferbroadleaf mixed forests. Greater decreases in resistance during severe drought events were associated with greater reductions in resilience. Although growth recovered in the next 4 years, only in stands with the three species were both resistance and recovery maintained during the next drought events. The stability in resistance and recovery (i.e., values close to 1.0) of stands under high-intensity overstorey removal conferred a higher resilience to both site groups. This is consistent with recent reviews linking mixing effects with growth in highly thinned stands. For example, Forrester and Bauhus (2016) suggested that mixing effects due to species-specific radial development and shade tolerance drive nutrient and water availability and determine the growth response in fir-sprucebeech stands. Additionally, other large-scale studies reported that drought resistance increases with the ratio of soil moisture to potential evapotranspiration (Gazol et al. 2017; StuartHaëntjens et al. 2018). In that sense, we observed an increase in drought resistance in stands with low total standing volume and fewer overstorey trees across the entire elevation gradient, indicating that higher water availability resulting from intensive overstorey removal may increase drought resistance. Drought recovery was higher in the short term (e.g., over 4 years) in stands maintaining high total standing volume and more overstorey trees. However, this enhanced growth capacity vanished fast. 


\subsection{Modelling adaptive forest management}

Process-based models are crucial to analyze the effects of forest structural changes on forest resilience to drought. Simulated growth dynamics should be sensitive to stand structural changes to test forest resilience. In ForClim, the structure representation satisfactorily captures the growth sensitivity of young trees to increases in light availability resulting from overstorey removal. Additionally, the simulations consider a vegetation-dependent water demand factor that relates the leaf area index to stand evapotranspiration (see Appendix 1; Elkin et al. 2015, Thrippleton et al. 2018). Thereby, overstorey removal reduced stand transpiration by diminishing foliage area. This, in combination with increased light availability for understorey trees, was particularly beneficial for shadetolerant species like silver fir (Grassi and Umberto Bagnaressi 2001). Furthermore, the integration of adaptive management strategies in a climate-sensitive forest gap model allowed us to test the effects of decreased resource competition and larger growth rate increment, as demonstrated by the differences among overstorey removal strategies. Although we have improved the representation of short-term drought effects on forest resilience and mortality (in ForClim), for longer drought periods, other issues (e.g., representation of carbon reserve pools; Guillemot et al. 2017) ought to be considered explicitly and by consideration of mechanisms, rather than heuristically as in our approach (cf. Appendix 1).

\subsection{The effect of forest composition and the geographical setting}

As mentioned above, mixtures of conifer and broadleaf tree species can improve forest resilience to drought. Reviewing thinning effects on temperate forests, Sohn et al. (2016b) found that individual-tree radial growth was on average $125 \%$ higher in heavily thinned compared to that in unthinned stands. They also found that soil water availability was $54 \%$ higher in heavily thinned compared to that in unthinned stands during a drought year. The positive effect of increased drought resilience in mixtures compared to monocultures has also been measured recently in closed even-aged, well to fully stock stands (Pardos et al. 2021). They found a strong positive effect of conifer-broadleaf mixed stands on drought resilience and resistance, and suggested that the considerably different root morphology and architecture among species leads to trait complementarity, thereby improving the exploitation of belowground resources. Conifer-conifer mixtures did not differ from monospecific conifer stands in terms of resistance and resilience, which could be linked to their greater similarities in traits and strategies to cope with drought (i.e., isohydric behavior). Similarly, in our simulations, the fir-spruce-beech combination was found to be more resistant and resilient to severe droughts than the fir-spruce stands.
The long-term resilience of mixed stands through overstorey removal was greatly affected by the elevational gradient and soil water holding capacity. Negative impacts from climate change are likely to occur in forests at low elevation $(\leq 1000$ $\mathrm{m}$ a.s.l). In contrast, high-elevation forests are more likely to benefit from warmer conditions in the absence of disturbances (Thrippleton et al. 2020). We observed that drought strongly affects volume growth across management strategies on lowand medium-elevation sites, especially those with low soil water holding capacity. Meanwhile, at high-elevation sites with high soil water holding capacity, only a slight effect was measured. These findings are consistent with the understanding that growth responses vary greatly according to topography, which plays a key role in altering stand water availability and determining local climate conditions, also according to aspect and slope (Zou et al. 2007). Individual trees feature specific mechanisms to maintain the integrity of their hydraulic system and avoid cavitation. In the short term, trees utilize dynamic and reversible regulation processes via these mechanisms, such as stomatal closure to reduce transpiration (Bréda et al. 2006). Our study demonstrates the short-term positive effects of adaptive forest management on the growth resilience of mixed forests, but the magnitude of the effect depends greatly on forest composition and the geographical setting. Reduced stand transpiration by high-intensity overstorey removal may help to regulate the negative impacts of climate change on low-elevation forests ( $\leq 1000 \mathrm{~m}$ a.s.l), increasing resistance, recovery, and resilience to drought conditions over 4-year periods (according to our state system baseline; Figure 3). Overall, an analysis of more experimental sites is necessary to support this conclusion across Central European temperate forests.

\subsection{Forest resilience economy}

The net present value was found to increase concurrently with the frequency and intensity of overstorey removal, offering a useful short-term management strategy to increase the economic efficiency of forest management. However, over longer periods and under changing growing conditions and different site qualities, density reduction responses may be overestimated (Pretzsch 2020). Elkin et al. (2015) showed that the effects of management are quickly disappearing in the growth response and would be rather costly to maintain via frequent interventions. The range of growth responses under different overstorey removal strategies in conifer-broadleaf stands (Figure 5) allows for the future exploration of different levels of frequency and intensity of overstorey reductions. This can provide insights to optimize drought-resilient forest economic efficiency. In comparison, overstorey removals in fir-spruce stands did not considerably affect their economic efficiency compared to BAU management, as lower MAI counterbalanced the effects of the early intensive interventions on NPV. The results of our economic efficiency analysis are in line with those of other authors 
such as Knoke et al. (2021). They used a framework of economic resilience and found that a forest management system with higher structural mixture (e.g., continuous cover forestry) performs economically and ecologically better than a monospecific system (e.g., clear fell). The economic resilience focuses on the time needed for a forest to gain the previous value after a disturbance. Another concept analyzed by Pukkala (2021) is using resilience and economic benefit in multi-criteria evaluation of the social benefit of forest management to rank alternative silvicultural systems. Notwithstanding, analyzing ecological and economic resilience is a useful framework for decisionmakers to evaluate the robustness of management regimes to deal with droughts.

It should be noted that we assumed fixed timber prices and a constant discount rate for the entire period to calculate the $\mathrm{NPV}$, ignoring that volatile prices and changes of the discount rate are an important source of risk for management investments (Knoke et al. 2001; Yousefpour et al. 2012). However, recent studies like Messerer et al. (2020) that used a simple modeling approach found that including empirical growth responses after harvest interventions greatly reduces the economic risk of optimized, uneven-aged forest management. Therefore, we recommend that future studies consider price and discount rate changes due to drought events or other disturbances in addition to process-based models.

This study contributes to the clarification that overstorey removal as an adaptation strategy may improve the ecological and economic efficiency in Central European conifer-broadleaf forests. Brèteau-Amores et al. (2019) illustrated the importance of considering ecological and economic benefits to evaluate drought-adaptation strategies. Moreover, Radke et al. (2020) recently demonstrated how combining economic metrics with ecological criteria (i.e., volume growth) can be used to delineate robust adaptive management practices. However, such joint analyses are largely lacking in the literature. Notwithstanding, our research further highlights the importance of increasing forest resilience for long-term adaptive management planning. Additional studies that simultaneously analyze resilience indices, mortality rates, and economic efficiency are crucial for the multi-dimensional evaluation of drought impacts and to identify the best drought management strategies.

\section{Conclusion}

In conclusion, the tested adaptive forest management strategies to remove overstorey trees are a promising strategy to increase ecological and economic resilience to severe drought events. Our study demonstrates the short-term positive effects of adaptive forest management on the growth resilience of mixed forests, but the magnitude of the effect depends greatly on forest composition and the geographical setting. However, the enhanced growth capacity vanished fast; therefore, the evaluation of adaptive forest management in the long term to compare the benefits from different strategies is required. Nevertheless, our study provides the highly relevant suggestion that under exacerbated drought conditions, maintaining unmanaged forests (i.e., the "do nothing" strategy) may not be an efficient strategy, especially because new and "advanced" regeneration will be negatively affected by drought conditions. This study shows an innovative combination of diverse historical data and forest models to address the potential consequences of drought in forest management under a framework of engineering, ecological, and economic resilience.

\section{Appendix 1}

\section{Summary for Appendix 1}

\begin{tabular}{|c|c|c|c|}
\hline $\begin{array}{l}\text { Section in } \\
\text { manuscript }\end{array}$ & Subsection & Item & Description \\
\hline \multirow[t]{8}{*}{ 2. Methods } & \multirow[t]{4}{*}{ 2.3. Improvements in ForClim } & Figure 8 & Effect of stand density on the evapotranspirative demand from vegetation \\
\hline & & $* * *$ & Growth function \\
\hline & & Table 3 & Minimum and maximum annual tree-ring width (TRW) ratios \\
\hline & & $* * *$ & Alternative background mortality \\
\hline & \multirow{2}{*}{$\begin{array}{l}\text { 2.4. Identification of severe drought } \\
\text { years }\end{array}$} & $* * *$ & Description of the process \\
\hline & & Figure 9 & Mean annual drought index \\
\hline & $\begin{array}{l}\text { Additional information on model } \\
\text { parameters }\end{array}$ & Table 4 & Site-specific parameters used in ForClim \\
\hline & $\begin{array}{l}\text { Additional data for the calculation of } \\
\text { economic indicators }\end{array}$ & Table 5 & $\begin{array}{l}\text { Average stumpage prices and harvesting costs for Baden-Württemberg for the period } \\
2000-2016 \text { by tree species and diameter class }\end{array}$ \\
\hline
\end{tabular}




\section{Improvements in ForClim v4.0.1.2}

Effect of stand density on the evapotranspirative demand from vegetation The evapotranspirative demand $(D)$ and water supply from the soil $(S)$ are the base of the drought index calculation in ForClim (Bugmann and Cramer 1998). Elkin et al. (2015) functionally coupled the vegetation leaf area index (LAI) to the water supply side to expand the framework and explicitly consider the effect of vegetation in calculating the drought index. That approach considered empirical data from Moreno and Cubera (2008), which estimated the lowest water use at an LAI $=0$ (unvegetated condition) and increased by $25 \%$ at an LAI $=8$ (dense stand). However, the new approach did not consider the evapotranspirative demand from different vegetation density levels like our research goals needed. To solve this issue, we use a function linking stand demand ( $\left.D_{\text {stand }}\right)$ to vegetation LAI via a vegetation-dependent demand factor $\left(F_{\text {vegetation }}\right)$ (see Eq. 5). The new equation was initially developed by Thrippleton et al. (2018) to account for the contribution of different stand vertical layers to the stand water demand in the spatially explicit model LandClim. The new demand factor is based on the original formulation in Bugmann and Cramer (1998) and in the empirical linear relationship between stand water use and LAI used in Elkin et al. (2015) (see Figure 8).

$D_{\text {stand }}=\left(P E T^{*} F_{\text {vegetation }}\right)-P_{\mathrm{i}}$

where $P E T$ is potential evapotranspiration (based on the approach of Thornthwaite and Mather, 1957) and $P_{\mathrm{i}}$ is the amount of water intercepted by the canopy (see Bugmann and Cramer (1998) and Thrippleton et al. (2018) for further details). Here, we present the linear equation used to calculate $F_{\text {vegetation, }}$, dependent on LAI (Eq. 6).

$F_{\text {vegetation }}=\min (0.75+0.03125 * \mathrm{LAI}, 1.0)$

In ForClim, LAI is sensitive to management interventions. Therefore, the vegetation-dependent demand factor for potential evapotranspiration in the stand is sensitive to stand density variations as needed for our research goals.
Fig. 8 Vegetation (LAI)dependent demand factor $\left(F_{\text {vegetation }}\right)$ for potential evapotranspiration in the stand (adapted from Elkin et al. 2015)

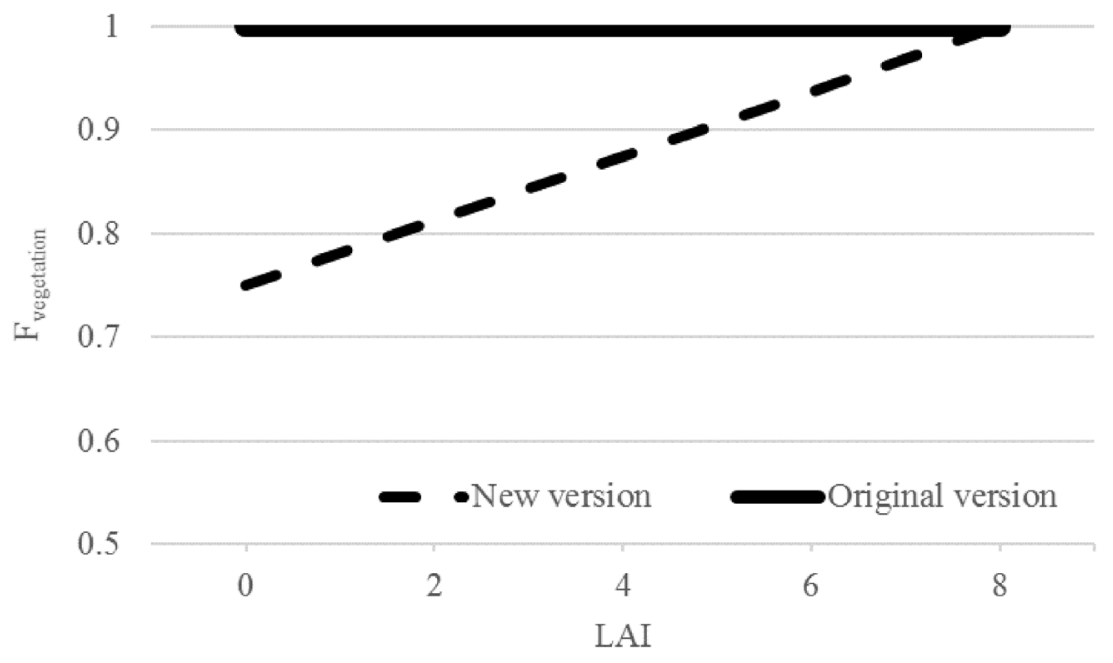

Growth function To avoid zero diameter increments in the model and constrain the estimations of resistance and recovery, we derived a minimum (and maximum) change of the diameter increment from one year to the next for each species using field data from research plots and implemented those thresholds in ForClim. Our calculation was based on the pancontinental tree-ring width (TRW) database by Cailleret et al. (2017) and on TRW measurements carried out at the study sites and analyzed following standard dendrochronological procedures (cf. Speer 2010). We then calculated the speciesspecific annual ratios of any two subsequent diameter increments, considering a minimum and maximum envelope of 99.9\% of the resulting data cloud to avoid extreme values (Table 3). The modified version of ForClim (v4.0.1.2) uses these measured TRW ratios to constrain the variability of simulated diameter increments from 1 year to the next when the simulated increment ratio is smaller or higher than the measured TRW ratio.

Alternative background mortality We used a size-dependent background mortality function rather than an age-dependent function to capture the vulnerability of large trees to climate warming (Stegen et al. 2011; Xu et al. 2017). The alternative theoretical function had already been tested in ForClim by Huber et al. (2020), with beneficial results.

\section{Identification of drought years using ForClim v4.0.1.2}

We used the mean annual drought index (uDrAn) in ForClim to identify drought years. To calculate the uDrAn, we used the 
Table 3 Minimum and maximum annual tree-ring width (TRW) ratios

\begin{tabular}{|c|c|c|c|c|c|}
\hline \multirow[t]{2}{*}{ Species } & \multicolumn{2}{|c|}{ TRW annual ratio } & \multirow[t]{2}{*}{ Number of sites } & \multirow[t]{2}{*}{ Number of trees cored } & \multirow[t]{2}{*}{ Number of rings measured } \\
\hline & Min & Max & & & \\
\hline Abies alba & 0.2 & 3.8 & 14 & 701 & 69,419 \\
\hline Picea abies & 0.2 & 5.4 & 28 & 961 & 118,149 \\
\hline Fagus sylvatica & 0.1 & 7 & 4 & 124 & 11,363 \\
\hline
\end{tabular}

monthly climate data from Dietrich et al. (2019). The index's positive values indicate an increase in yearly potential evapotranspiration and/or decreased precipitation (Figure 9). Strong drought effects were simulated in sites with lower soil water potential (i.e., $\mathrm{BS}<14 \mathrm{~cm}$, steep to moderate slope; sites 221 ,
224,225 ). Sites with higher soil water potential (i.e., $B S=20$ $\mathrm{cm}$, moderate to flat slope; sites 220, 222, 223) showed smaller drought effects. For the identification of drought years, we identified years with $\mathrm{uDrAn}>0.2$ as severe drought events (i.e., years 2003 and 2016); then, we selected years with values
Fig. 9 Mean annual drought index (uDrAn) under BAU strategy along the elevation gradient. Vertical gray lines indicate the identified drought years (i.e., 1983, 1991, 2003, 2006, and 2016)

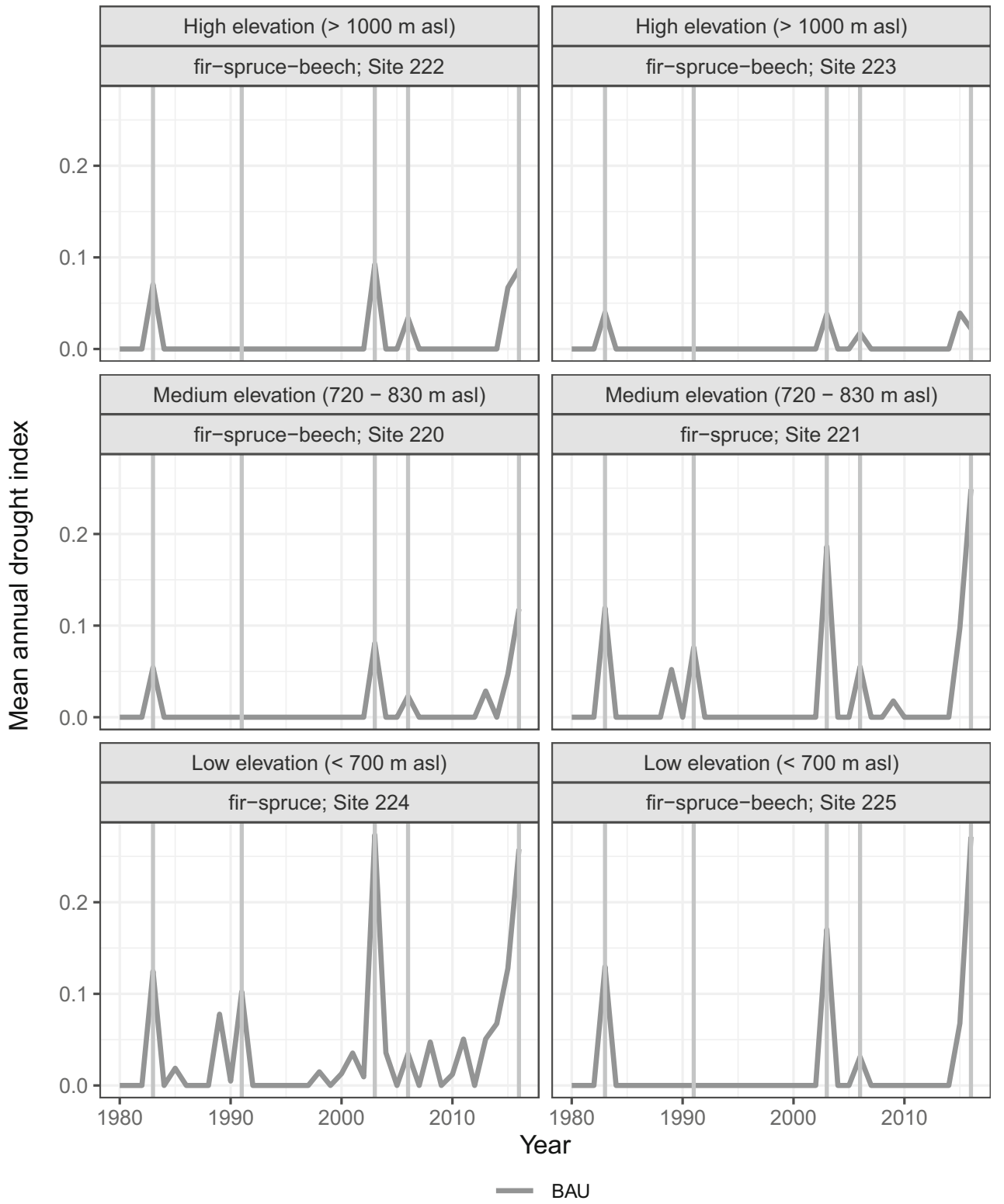


Table 4 Site-specific parameters used in the ForClim simulations for this study

\begin{tabular}{lllllll}
\hline & \multicolumn{2}{l}{ Study sites } & & & & \\
\cline { 2 - 7 } & 220 & 221 & 222 & 223 & 224 & 225 \\
\hline Bucket size $(\mathrm{cm})$ & 20 & 12 & 20 & 20 & 14 & 14 \\
Nitrogen $\left(\mathrm{kg} \mathrm{ha}^{-1}\right.$ year $\left.^{-1}\right)$ & 100 & 70 & 90 & 90 & 90 & 70 \\
Browsing pressure $(\%)$ & 90 & 80 & 80 & 80 & 70 & 80 \\
\hline
\end{tabular}

$0.1<\mathrm{uDrAn}<0.2$ as mild droughts (i.e., years 1983 and 1991) and finally for values $0<\mathrm{uDrAn}<0.1$ consistent at all sites as mild droughts (i.e., year 2006).

\section{Additional information on model parameters in ForClim v4.0.1.2}

The values in Table 4 indicate site-specific environmental and biotic conditions that act as species-specific limitations for sapling $(\mathrm{dbh}=1.27 \mathrm{~cm})$ establishment (e.g., browsing pressure, soil moisture derived from the bucket size), and tree growth reduction factors (e.g., nitrogen availability, soil moisture derived from the bucket size). The values are based on data provided by Forstliche Versuchs- und Forschungsanstalt Baden-Württemberg (FVA).

\section{Additional data for the calculation of economic indicators}

Table 5 Average stumpage prices and harvesting costs for BadenWürttemberg for the period 2000-2016 by tree species and diameter class

\begin{tabular}{lllll}
\hline & $\begin{array}{l}\text { Diameter class } \\
(\mathrm{cm})\end{array}$ & $\begin{array}{l}\text { Price } \\
\left(€ / \mathrm{m}^{3}\right)\end{array}$ & $\begin{array}{l}\text { Harvesting } \\
\text { costs } \\
\left(€ / \mathrm{m}^{3}\right)\end{array}$ & $\begin{array}{l}\text { Net } \\
\text { income } \\
\left(€ / \mathrm{m}^{3}\right)\end{array}$ \\
\hline Norway spruce & $0-7$ & 21 & -21 \\
& $7-10$ & 10.00 & 21 & -11 \\
$10-15$ & 44.04 & 21 & 23 \\
$15-20$ & 64.53 & 22 & 43 \\
$20-25$ & 71.76 & 20 & 52 \\
$25-30$ & 78.12 & 19 & 59 \\
$30-35$ & 78.26 & 18 & 60 \\
$35-40$ & 77.56 & 17 & 61 \\
$40-50$ & 74.79 & 16 & 59 \\
$50-60$ & 68.03 & 17 & 51 \\
$>60$ & 60.11 & 17 & 43 \\
& 35.01 & 21 & 14 \\
\hline
\end{tabular}

Table 5 (continued)

\begin{tabular}{|c|c|c|c|c|}
\hline & $\begin{array}{l}\text { Diameter class } \\
(\mathrm{cm})\end{array}$ & $\begin{array}{l}\text { Price } \\
\left(€ / \mathrm{m}^{3}\right)\end{array}$ & $\begin{array}{l}\text { Harvesting } \\
\text { costs } \\
\left(€ / \mathrm{m}^{3}\right)\end{array}$ & $\begin{array}{l}\text { Net } \\
\text { income } \\
\left(€ / \mathrm{m}^{3}\right)\end{array}$ \\
\hline \multirow{15}{*}{$\begin{array}{l}\text { Fagus } \\
\quad \text { sylvatica }\end{array}$} & $\begin{array}{l}\text { Industrial } \\
\text { wood }\end{array}$ & & & \\
\hline & Fuel wood & 10.00 & 0 & 10 \\
\hline & $0-7$ & & 21 & -21 \\
\hline & $7-10$ & 20.00 & 26 & -6 \\
\hline & $10-15$ & 21.60 & 26 & -4 \\
\hline & $15-20$ & 33.82 & 25 & 9 \\
\hline & $20-25$ & 36.17 & 22 & 14 \\
\hline & $25-30$ & 44.61 & 21 & 24 \\
\hline & $30-35$ & 57.19 & 19 & 38 \\
\hline & $35-40$ & 66.82 & 18 & 49 \\
\hline & $40-50$ & 76.45 & 16 & 60 \\
\hline & $50-60$ & 94.37 & 18 & 76 \\
\hline & $>60$ & 104.89 & 18 & 87 \\
\hline & $\begin{array}{l}\text { Industrial } \\
\text { wood }\end{array}$ & 33.31 & 26 & 7 \\
\hline & Fuel wood & 20.00 & 0 & 20 \\
\hline \multirow[t]{13}{*}{ Silver fir } & $0-7$ & & 21 & -21 \\
\hline & $7-10$ & 10.00 & 21 & -11 \\
\hline & $10-15$ & 38.57 & 21 & 18 \\
\hline & $15-20$ & 61.47 & 22 & 40 \\
\hline & $20-25$ & 68.18 & 20 & 48 \\
\hline & $25-30$ & 73.74 & 19 & 55 \\
\hline & $30-35$ & 74.01 & 18 & 56 \\
\hline & $35-40$ & 72.80 & 17 & 56 \\
\hline & $40-50$ & 71.10 & 16 & 55 \\
\hline & $50-60$ & 67.23 & 17 & 50 \\
\hline & $>60$ & 67.96 & 17 & 51 \\
\hline & $\begin{array}{l}\text { Industrial } \\
\text { wood }\end{array}$ & 35.01 & 21 & 14 \\
\hline & Fuel wood & 10.00 & 0 & 10 \\
\hline
\end{tabular}

\section{References of Appendix 1}

1. Bugmann, Harald; Cramer, Wolfgang (1998) Improving the behaviour of forest gap models along drought gradients. In Forest Ecology and Management 103 (Allen et al. 2010; Anderegg et al. 2015), pp. 247-263. DOI: 10.1016/S0378-1127(97)00217-X.

2. Bugmann, Harald K. M. (1996) A simplified forest model to study species composition along climate gradients. In Ecology 77 (Bose et al. 2018), pp. 2055-2074.

3. Cailleret, Maxime; Jansen, Steven; Robert, Elisabeth M. R.; Desoto, Lucía; Aakala, Tuomas; Antos, Joseph A. et al. (2017) A synthesis of radial growth patterns preceding tree mortality. In Global change biology 23 
(Bennett et al. 2015), pp. 1675-1690. DOI: 10.1111/ gcb.13535.

4. Dietrich, Helge; Wolf, Thilo; Kawohl, Tobias; Wehberg, Jan; Kändler, Gerald; Mette, Tobias et al. (2019) Temporal and spatial high-resolution climate data from 1961 to 2100 for the German National Forest Inventory (NFI). In Annals of Forest Science 76 (Allen et al. 2015), p. 171. DOI: 10.1007/s13595-018-0788-5.

5. Elkin, Ché; Giuggiola, Arnaud; Rigling, Andreas; Bugmann, Harald (2015) Short- and long-term efficacy of forest thinning to mitigate drought impacts in mountain forests in the European Alps. In Ecological Applications 25 (Bennett et al. 2015), pp. 1083-1098. DOI: 10.1890/14-0690.1.

6. Huber, Nica; Bugmann, Harald; Lafond, Valentine (2020) Capturing ecological processes in dynamic forest models. Why there is no silver bullet to cope with complexity. In Ecosphere 11 (Berntson and Wayne 2000), p. 1. DOI: $10.1002 /$ ecs2.3109.

7. Moreno G, Cubera E. (2008) Impact of stand density on water status and leaf gas exchange in Quercus ilex. Forest Ecology and Management 254: 74-84.

8. Speer, James H. (2010) Fundamentals of tree-ring research. Tucson, Ariz.: Univ. of Arizona Press.
9. Stegen, James C.; Swenson, Nathan G.; Enquist, Brian J.; White, Ethan P.; Phillips, Oliver L.; Jørgensen, Peter M. et al. (2011) Variation in above-ground forest biomass across broad climatic gradients. In Global Ecology and Biogeography 20 (Berntson and Wayne 2000), pp. 744-754. DOI: 10.1111/j.1466-8238.2010.00645.x.

10. Thornthwaite CW, Mather J.R. (1957) Instructions and tables for computing potential evapotranspiration and the water balance. Publications in climatology 10: 183311

11. Thrippleton, Timothy; Bugmann, Harald; Folini, Marc; Snell, Rebecca S. (2018) Overstory-understorey interactions intensify after drought-induced forest die-off. Long-term effects for forest structure and composition. In Ecosystems 21 (Bennett et al. 2015), pp. 723-739. DOI: 10.1007/s10021-017-0181-5.

12. Xu, Kai; Wang, Xiangping; Liang, Penghong; An, Hailong; Sun, Han; Han, Wei; Li, Qiaoyan (2017) Tree-ring widths are good proxies of annual variation in forest productivity in temperate forests. In Scientific reports 7 (Allen et al. 2015), p. 1945. DOI: 10.1038/ s41598-017-02022-6.

\section{Appendix 2}

\section{Summary for Appendix 2}

\begin{tabular}{|c|c|c|c|}
\hline $\begin{array}{l}\text { Section in } \\
\quad \text { manuscript }\end{array}$ & Subsection & Item & Description \\
\hline \multirow[t]{12}{*}{ 3. Results } & 3.1. Model evaluation & Table 6 & Percentage of bias \\
\hline & & Table 7 & Root mean squared error \\
\hline & 3.2. Model application & Figure 10 & Standing volume under BAU \\
\hline & 3.3.1. Resilience, resistance, recovery, and management strategies & Figure 11 & Differences in forest resistance \\
\hline & & Figure 12 & Differences in forest recovery \\
\hline & 3.3.2. Resilience, resistance, recovery, and forest composition & Figure 13 & Forest resistance to drought \\
\hline & & Figure 14 & Forest recovery from drought \\
\hline & 3.4. Mortality & Figure 15 & Differences in mean dbh of living and dead trees \\
\hline & 3.5. Economic assessment: sensitivity analysis of economic results & Table 8 & Averaged NPV, discount rate $1 \%$ \\
\hline & & Table 9 & Averaged LEV, discount rate $1 \%$ \\
\hline & & Table 10 & Averaged NPV, discount rate $2 \%$ \\
\hline & & Table 11 & Averaged LEV, discount rate $2 \%$ \\
\hline
\end{tabular}

\section{Model evaluation}

Evaluation methods To evaluate the simulation result goodness-of-fit against the inventory measurements, we used root mean standard error (RMSE, Eq. 7) and percentage of bias (pbias, Eq. 8). We computed indices for basal area, standing volume, number of trees, and mean tree dbh and height of the dominant trees (100 tallest trees in the stand) to evaluate the simulations. Both indices are computed for every site under the business as usual (BAU) strategy: 


$$
\begin{aligned}
& \text { RMSE }=\frac{\sqrt{\sum(s i m-o b s)^{2} /(n-1)}}{\sum o b s / n} * 100 \\
& \text { PBIAS }=\frac{\sum(\text { sim-obs }) / n}{\sum o b s / n} * 100
\end{aligned}
$$

where sim is the result of the model for the inventory year and $o b s$ is the measurement in the inventory. We considered the total number of measurements in the inventory (the inventory includes measurements every 5 years approximately).
Table 6. Percentage of bias (pbias) between inventory observations and simulations of BAU (control interventions or the removal of $50 \%$ of the 10 -year volume increment for trees with a $\mathrm{dbh} \geq 10 \mathrm{~cm}$, for every site)

\begin{tabular}{lllllll}
\hline \multirow{2}{*}{ Site } & Composition & \multicolumn{2}{l}{ pbias (\%) } & & \\
\cline { 3 - 6 } & & Basal area & Standing volume & Number of trees & Tree DBH & Tree height \\
\hline 220 & Fir-spruce-beech* & -0.6 & -4.7 & 3.6 & -3.3 & -4.9 \\
221 & Fir-spruce & -1.9 & 0.6 & 1.8 & -8.3 & 10.8 \\
222 & Fir-spruce-beech & -0.1 & -4.2 & -2.4 & -9.0 & -1.4 \\
223 & Fir-spruce-beech & 0.2 & 0.5 & -4.5 & -9.0 & 3.6 \\
224 & Fir-spruce & -0.8 & -2.5 & 6.3 & -7.4 & 1.3 \\
225 & Fir-spruce-beech & 1.5 & -3.6 & -0.9 & -4.3 & 3.7 \\
\hline
\end{tabular}

*fir silver fir, spruce Norway spruce, beech European beech

\begin{tabular}{lllllll}
\hline \multirow{2}{*}{ Site } & Composition & \multicolumn{2}{l}{ RMSE (\%) } & & \\
\cline { 3 - 6 } & & Basal area & Standing volume & Number of trees & Tree DBH & Tree height \\
\hline 220 & Fir-spruce-beech* & 0.7 & 5.3 & 4.1 & 3.7 & 5.8 \\
221 & Fir-spruce & 2.2 & 0.7 & 2.1 & 9.4 & 12.3 \\
222 & Fir-spruce-beech & 0.1 & 4.7 & 2.7 & 10.1 & 1.6 \\
223 & Fir-spruce-beech & 0.2 & 0.6 & 5.1 & 10.1 & 4.0 \\
224 & Fir-spruce & 0.8 & 2.9 & 7.0 & 8.3 & 1.5 \\
225 & Fir-spruce-beech & 1.7 & 4.1 & 1.1 & 4.9 & 4.2 \\
\hline
\end{tabular}

*fir silver fir, spruce Norway spruce, beech European beech
Table 7 Root mean standard error (RMSE) between inventory observations and simulations of BAU (control interventions or the removal of $50 \%$ of the 10 -year volume increment for trees with a $\mathrm{dbh} \geq 10 \mathrm{~cm}$, for every site) 


\section{Additional evaluation results}

Fig. 10 Simulated standing volume $\left(\mathrm{m}^{3} \mathrm{ha}^{-1}\right)$ under business as usual (BAU) strategy: control interventions (removal of $50 \%$ of the 10 -year volume increment for trees $\geq 10 \mathrm{~cm}$ in dbh). Black circles represent the measured values in the inventory every 5 years. Circles in 1979, for sites 220-223, and 1980, for sites 224 225 , represent the model initialization values. Values in the labels indicate measures for goodness-of-fit, including all the inventory measurements
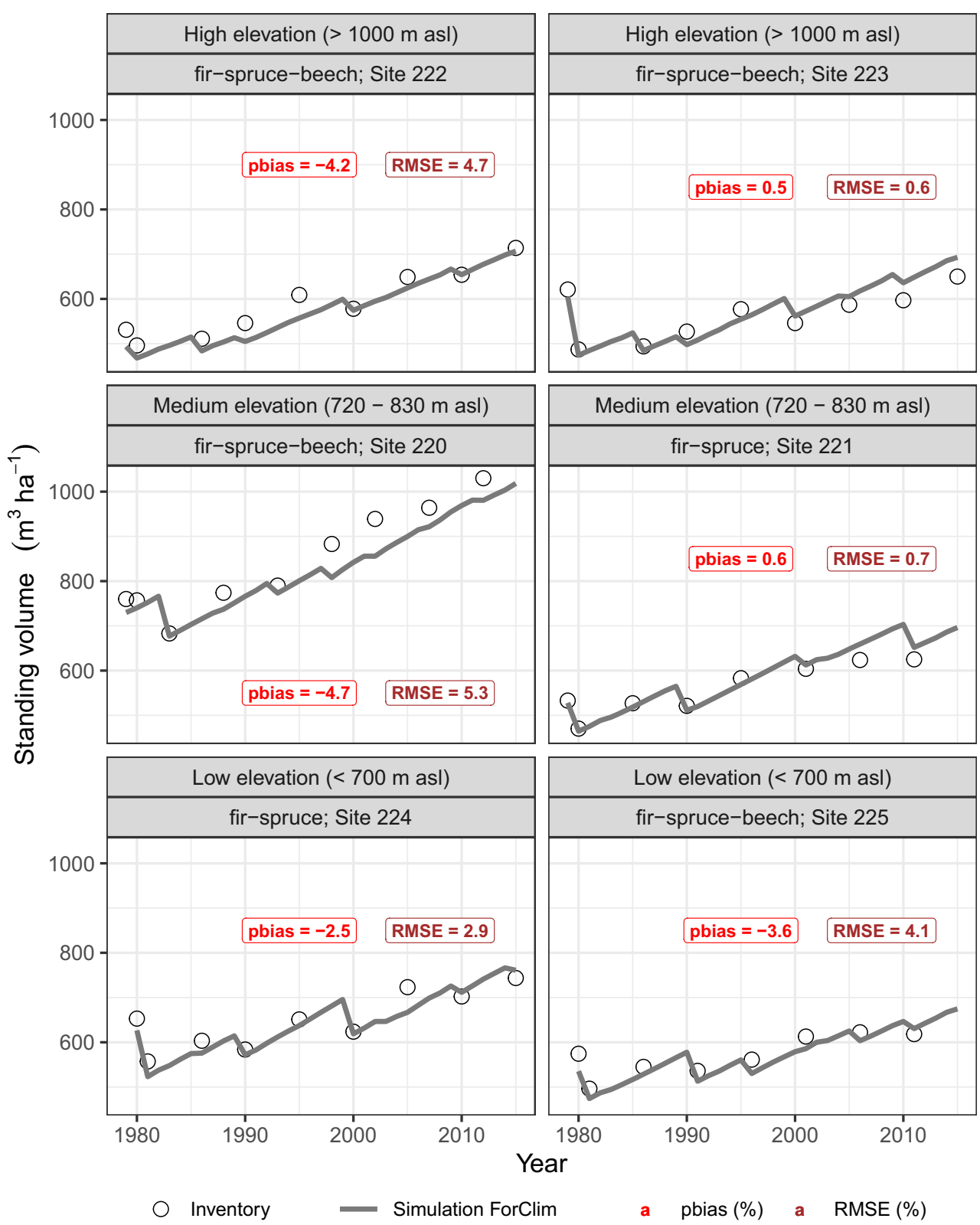

Inventory

Simulation ForClim

a pbias (\%) a RMSE (\%) 


\section{Model application}

Fig. 11 Differences in forest resistance of remaining trees after management strategies during drought years. Forest resistance was calculated using the average MAI of 4 years pre-drought as system state baseline. To

calculate the resistance to the drought of 1983, we used 2 years as the baseline because the simulations started in 1980-1981 only
Fig. 12 Differences in forest recovery of remaining trees after management strategies during drought years. Forest recovery was calculated using the average MAI of 4 years post-drought as system state baseline. To calculate the recovery from the drought of 2016, the model was run until 2020
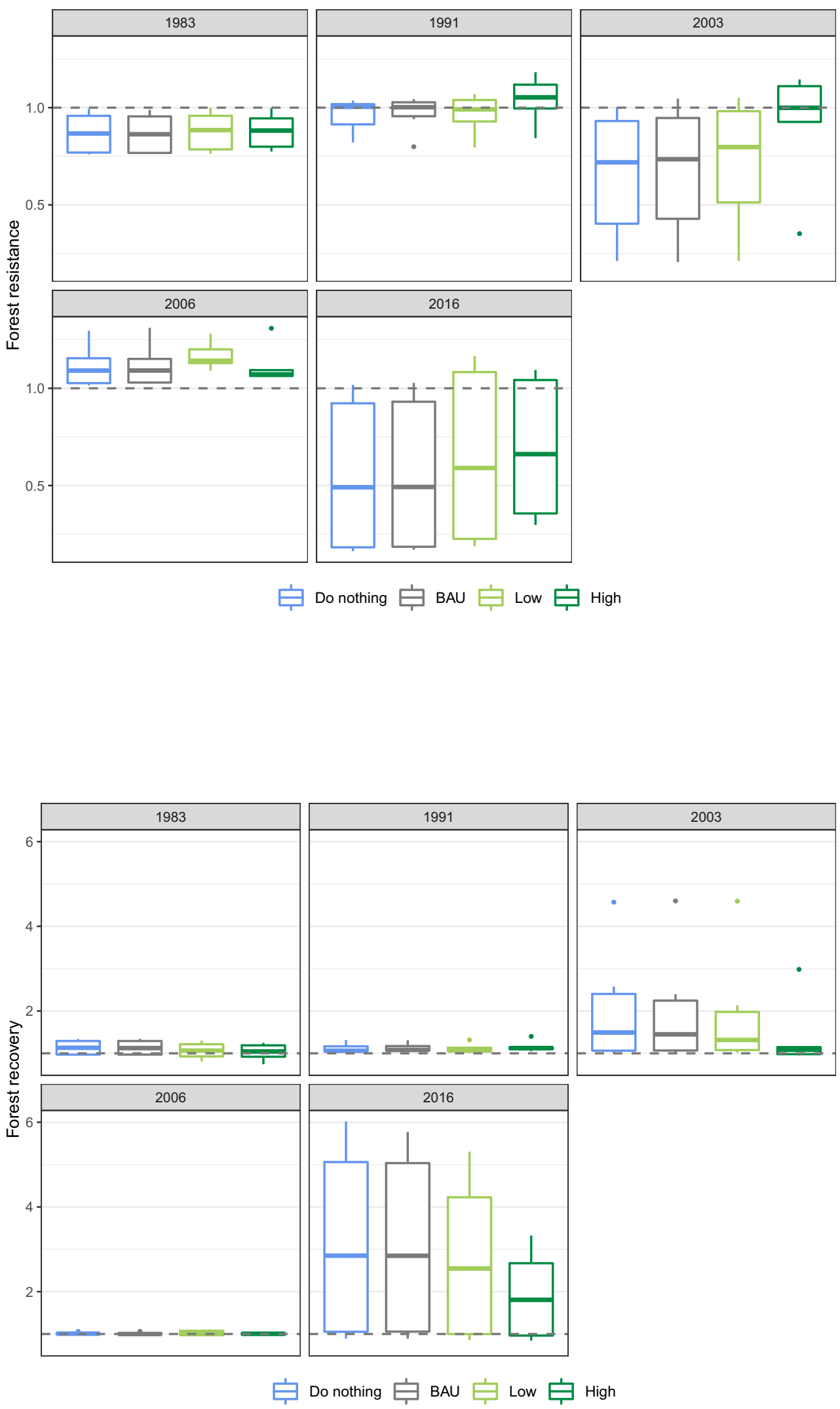
Fig. 13 Forest resistance to drought of the remaining trees after management strategies separated by species composition. Resistance $=1$ : the average growth rate before the drought was maintained after the drought event. Resistance $>1$ : the growth rate was increased after the drought event. Resistance $<1$ : the growth rate was decreased after the drought event. Gray vertical lines indicate drought years (1983, 1991, 2003, 2006, and 2016). The values were averaged over stands composed of firspruce-beech and fir-spruce trees
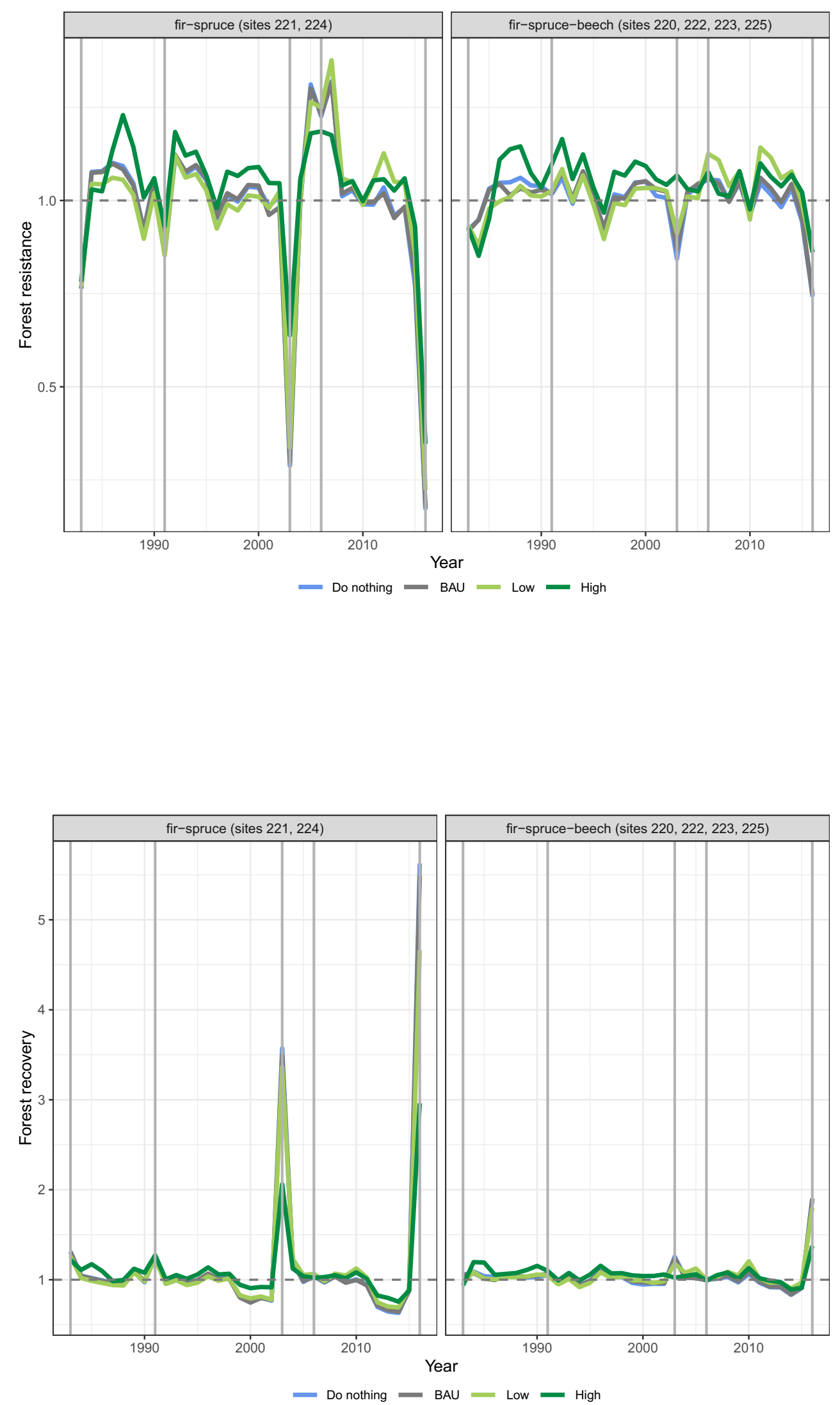

Do nothing $=$ BAU $=$ Low - High
Fig. 14 Forest recovery of remaining trees after management strategies separated by species composition. Recovery $=1$ : the average growth rate before the drought was maintained after the drought event. Recovery $>1$ : the growth rate was increased after the drought event. Recovery $<1$ : the growth rate was decreased after the drought event. Gray vertical lines indicate drought years $(1983,1991,2003,2006$, and 2016). The values were averaged over stands composed of fir-spruce-beech and fir-spruce trees 
Fig. 15 Differences in mean diameter at breast height (dbh, $\mathrm{cm}$ ) of living trees (points) and dead trees by stress-induced mortality (solid line) under four management strategies. Results of mortality are accumulated over 4 years, while living trees are represented annually. Vertical gray lines indicate drought years (1983, 1991, 2003, 2006, and 2016)
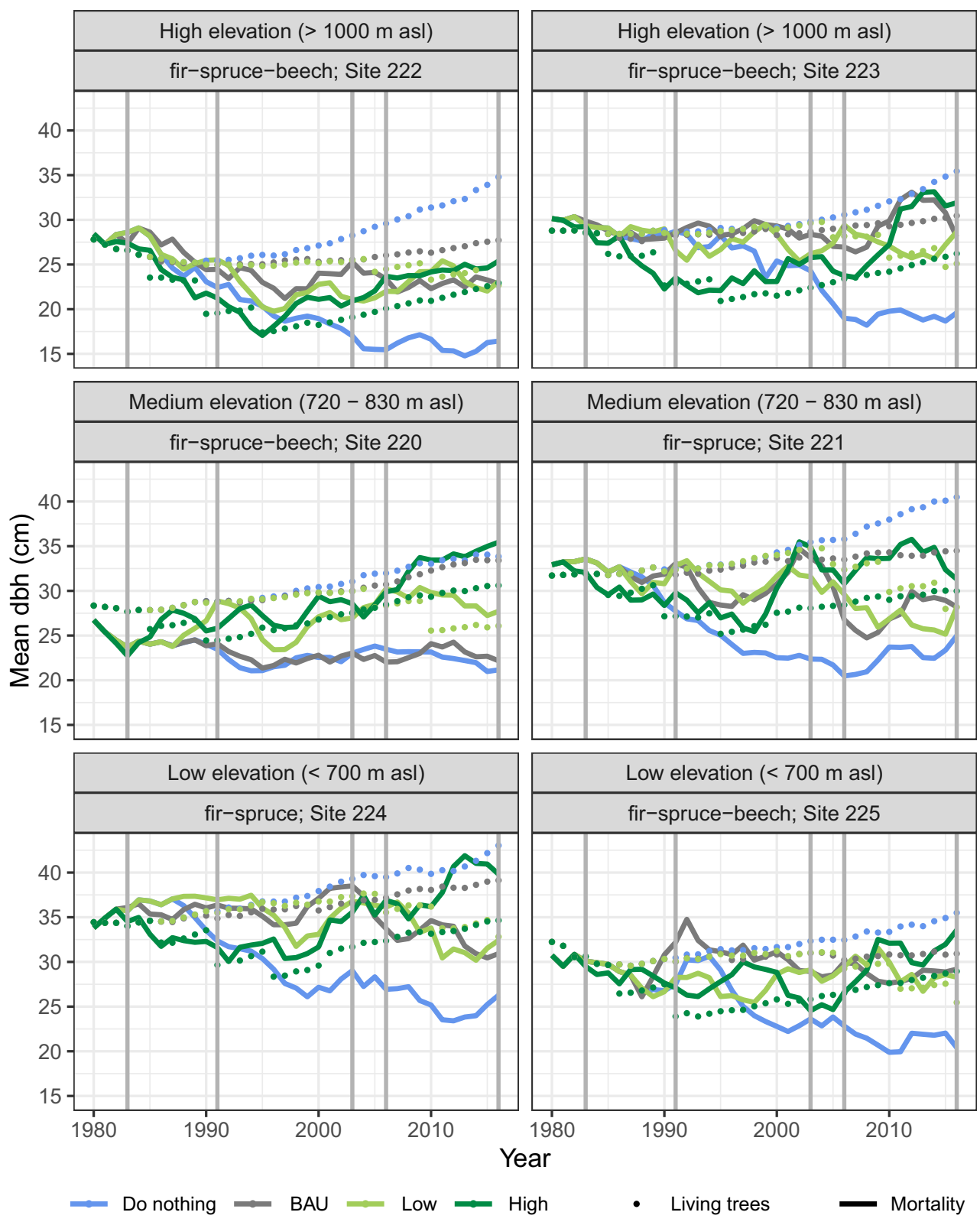


\section{Sensitivity analysis of economic results}

Table 8 Average net present value (NPV) according to site and management strategy. The values of NPV were calculated with an interest rate of $1 \%$, using averaged stumpage prices and harvesting costs for Baden-Württemberg for the period 2000-2016 (see Appendix Table 5). We calculated NPV in euros per hectare and averaged for the period 1980-2016

\begin{tabular}{lllll}
\hline Site & \multicolumn{4}{l}{ Net present value, $1 \%$ discount rate $(€$ ha- 1$)$} \\
\cline { 2 - 5 } & "Do nothing" & BAU & Low intensity & High intensity \\
\hline 220 & $2266.9 €$ & $2397.5 €$ & $2787.3 €$ & $3571.8 €$ \\
221 & $8189.0 €$ & $8655.5 €$ & $8618.5 €$ & $8925.8 €$ \\
222 & $3613.5 €$ & $3775.5 €$ & $4013.3 €$ & $4825.9 €$ \\
223 & $9445.2 €$ & $9426.7 €$ & $9571.3 €$ & $10,864.1 €$ \\
224 & $10,814.6 €$ & $11,210.6 €$ & $11,124.0 €$ & $11,684.8 €$ \\
225 & $7465.9 €$ & $7631.5 €$ & $7800.4 €$ & $8428.2 €$ \\
\hline
\end{tabular}

Table 9 Average land expectation value (LEV) according to site and management strategy. The values of LEV were calculated with an interest rate of $1 \%$, using averaged stumpage prices and harvesting costs for Baden-Württemberg for the period 2000-2016 (see Appendix Table 5). We calculated LEV in euros per hectare and averaged for the period 1980-2016. The LEV is showed as a comparison with NPV

\begin{tabular}{lllll}
\hline Site & \multicolumn{4}{l}{ Land expectation value, $1 \%$ discount rate $\left(€ \mathrm{ha}^{-1}\right)$} \\
\cline { 2 - 5 } & "Do nothing" & BAU & Low intensity & High intensity \\
\hline 220 & $7529.4 €$ & $7963.0 €$ & $9257.7 €$ & $11,863.6 €$ \\
221 & $27,199.1 €$ & $28,748.5 €$ & $28,625.6 €$ & $29,646.3 €$ \\
222 & $12,001.8 €$ & $12,540.1 €$ & $13,329.7 €$ & $16,028.8 €$ \\
223 & $31,371.6 €$ & $31,310.1 €$ & $31,790.4 €$ & $36,084.3 €$ \\
224 & $36,773.8 €$ & $38,120.1 €$ & $37,825.6 €$ & $39,732.6 €$ \\
225 & $25,387.0 €$ & $25,950.0 €$ & $26,524.2 €$ & $28,658.9 €$
\end{tabular}

Table 10 Average net present value (NPV) according to site and management strategy. The values of NPV were calculated with an interest rate of $2 \%$, using averaged stumpage prices and harvesting costs for Baden-Württemberg for the period 2000-2016 (see Appendix Table 5). We calculated NPV in euros per hectare and averaged for the period 1980-2016. The NPV using a $2 \%$ discount rate shows the sensitivity of the economic results to the discount rate chosen

\begin{tabular}{lcrcr}
\hline Site & \multicolumn{4}{l}{ Net present value, $2 \%$ discount rate $\left(€\right.$ ha $\left.^{-1}\right)$} \\
\cline { 2 - 5 } & "Do nothing" & BAU & Low intensity & High intensity \\
\hline 220 & $-4111.4 €$ & $-3961.9 €$ & $-3361.7 €$ & $-499.3 €$ \\
221 & $3153.8 €$ & $3812.3 €$ & $3830.9 €$ & $5714.2 €$ \\
222 & $-694.9 €$ & $-311.5 €$ & $-95.7 €$ & $1995.8 €$ \\
223 & $4754.7 €$ & $5141.8 €$ & $5153.9 €$ & $7660.8 €$ \\
224 & $5354.6 €$ & $6070.4 €$ & $5958.1 €$ & $8228.7 €$ \\
225 & $2846.2 €$ & $3304.0 €$ & $3398.5 €$ & $5425.8 €$ \\
\hline
\end{tabular}

Table 11 Average land expectation value (LEV) according to site and management strategy. The values of LEV were calculated with an interest rate of $2 \%$, using averaged stumpage prices and harvesting costs for Baden-Württemberg for the period 2000-2016 (see Appendix Table 5). We calculated LEV in euros per hectare and averaged for the period 1980-2016. The LEV is showed as a comparison with NPV. The LEV using a $2 \%$ discount rate shows the sensitivity of the economic results to the discount rate chosen

\begin{tabular}{lrrrr}
\hline Site & \multicolumn{4}{l}{ Land expectation value, $2 \%$ discount rate $\left(€ \mathrm{ha}^{-1}\right)$} \\
\cline { 2 - 5 } & "Do nothing" & \multicolumn{1}{c}{ BAU } & Low intensity & High intensity \\
\hline 220 & $-8065.1 €$ & $-7771.8 €$ & $-6594.4 €$ & $-979.5 €$ \\
221 & $6186.7 €$ & $7478.4 €$ & $7514.8 €$ & $11,209.2 €$ \\
222 & $-1363.1 €$ & $-611.1 €$ & $-187.6 €$ & $3915.0 €$ \\
223 & $9327.0 €$ & $10,086.3 €$ & $10,110.0 €$ & $15,027.8 €$ \\
224 & $10,709.8 €$ & $12,141.5 €$ & $11,916.8 €$ & $16,458.2 €$ \\
225 & $5692.8 €$ & $6608.3 €$ & $6797.3 €$ & $10,852.2 €$ \\
\hline
\end{tabular}

Acknowledgements We thank Tilo Wolff(F.V.A.) for providing data for model initialization and historical simulations. Nica Huber, Dominic Michel, and Timothy Thrippleton (ETH-Zürich) are gratefully acknowledged for their collaboration in the modifications of ForClim. Alessandra Bottero (W.S.L.) is gratefully acknowledged for the data collection and analysis of dendroecological samples used to develop the diameter increment constraints. We are grateful to the two reviewers and the handling editor for their recommendations to improve the manuscript.

Funding Open Access funding enabled and organized by Projekt DEAL. Funding for this research was provided by the ForRISK project (ERANET Sumforest). Sumforest was funded by the European Union under Grant Agreement No. 606803. The ERA-NET Sumforest project ForRISK was funded in Switzerland through the Federal Office for the Environment FOEN (Grant No. 05.0602.PZ/P382-0487), in France through the French National Research Agency A.N.R. (Grant No. ANR-16-SUMF-0001-01), and in Germany through the Federal Ministry for Food and Agriculture BMEL (F.K.Z.: 2816ERA04S).

Availability of data and material The datasets generated or analyzed during the current study are available from the corresponding author on reasonable request.

\section{Declarations}

Consent for publication All the authors gave their informed consent to this publication and its content.

Conflict of interest The authors declare no competing interests.

Open Access This article is licensed under a Creative Commons Attribution 4.0 International License, which permits use, sharing, adaptation, distribution and reproduction in any medium or format, as long as you give appropriate credit to the original author(s) and the source, provide a link to the Creative Commons licence, and indicate if changes were made. The images or other third party material in this article are included in the article's Creative Commons licence, unless indicated otherwise in a credit line to the material. If material is not included in the article's 
Creative Commons licence and your intended use is not permitted by statutory regulation or exceeds the permitted use, you will need to obtain permission directly from the copyright holder. To view a copy of this licence, visit http://creativecommons.org/licenses/by/4.0/.

\section{References}

Allen CD, Macalady AK, Chenchouni H, Bachelet D, McDowell N, Vennetier M, Kitzberger T, Rigling A, Breshears DD, Hogg EH(T), Gonzalez P, Fensham R, Zhang Z, Castro J, Demidova N, Lim J-H, Allard G, Running SW, Semerci A, Cobb N (2010) A global overview of drought and heat-induced tree mortality reveals emerging climate change risks for forests. For Ecol Manag 259(4): 660-684. https://doi.org/10.1016/j.foreco.2009.09.001

Allen CD, Breshears DD, McDowell NG (2015) On underestimation of global vulnerability to tree mortality and forest die-off from hotter drought in the Anthropocene. Ecosphere 6(8). Available online at https://doi.org/10.1890/ES15-00203

Anderegg WRL, Hicke JA, Fisher RA, Allen CD, Aukema J, Bentz B, Hood S, Lichstein JW, Macalady AK, McDowell N, Pan Y, Raffa K, Sala A, Shaw JD, Stephenson NL, Tague C, Zeppel M (2015) Tree mortality from drought, insects, and their interactions in a changing climate. The New phytologist 208(3):674-683. https:// doi.org/10.1111/nph.13477

Bennett AC, McDowell NG, Allen CD, Anderson-Teixeira KJ (2015) Larger trees suffer most during drought in forests worldwide. In Nature plants 1:15139. https://doi.org/10.1038/nplants.2015.139

Berntson GM, Wayne PM (2000) Characterizing the size dependence of resource acquisition within crowded plant populations. Ecology 81(4):1072-1085

Bircher N, Cailleret M, Bugmann H (2015) The agony of choice. different empirical mortality models lead to sharply different future forest dynamics. In Ecological applications : a publication of the Ecological Society of America 25(5):1303-1318

Bose AK, Weiskittel A, Kuehne C, Wagner RG, Turnblom E, Burkhart HE (2018) Tree-level growth and survival following commercial thinning of four major softwood species in North America. In Forest Ecology and Management 427:355-364. https://doi.org/10. 1016/j.foreco.2018.06.019

Bréda N, Huc R, Granier A, Dreyer E (2006) Temperate forest trees and stands under severe drought. A review of ecophysiological responses, adaptation processes and long-term consequences. In Ann For Sci 63(6):625-644. https://doi.org/10.1051/forest:2006042

Brèteau-Amores S, Brunette M, Davi H (2019) An economic comparison of adaptation strategies towards a drought-induced risk of forest decline. Ecol Econ 164. Available online at https://doi.org/10. 1016/j.ecolecon.2019.04.006

Bugmann HKM (1996) A simplified forest model to study species composition along climate gradients. Ecology 77(7):2055-2074

Bugmann HKM (2001) A review of forest gap models. In Climatic Change 51:259-305

Bugmann H, Cramer W (1998) Improving the behaviour of forest gap models along drought gradients. For Ecol Manag 103(2-3):247263. https://doi.org/10.1016/S0378-1127(97)00217-X

Bugmann HK, Wullschleger SD, Price DT, Ogle K, Clark DF, Solomon AM (2001) Comparing the performance of forest gap models in North America. In Climatic Change 51:349-388

DeSoto L, Cailleret M, Sterck F, Jansen S, Kramer K, Robert EMR et al (2020) Low growth resilience to drought is related to future mortality risk in trees. In Nature communications 11(1):545. https://doi. org/10.1038/s41467-020-14300-5

Development Core Team R (2019) R: A language and environment for statistical computing. R Foundation for Statistical Computing, Vienna, Austria
Didion M, Kupferschmid AD, Zingg A, Fahse L, Bugmann H (2009) Gaining local accuracy while not losing generality - extending the range of gap model applications. In Can J For Res 39(6): 1092-1107. https://doi.org/10.1139/X09-041

Dietrich H, Wolf T, Kawohl T, Wehberg J, Kändler G, Mette T et al (2019) Temporal and spatial high-resolution climate data from 1961 to 2100 for the German National Forest Inventory (NFI). In Annals of Forest Science 76(1):171. https://doi.org/10.1007/ s13595-018-0788-5

Dittmar C, Zech W, Elling W (2003) Growth variations of common beech (Fagus sylvatica L.) under different climatic and environmental conditions in Europe. a dendroecological study. In Forest Ecology and Management 173:63-78

Elkin C, Giuggiola A, Rigling A, Bugmann H (2015) Short- and longterm efficacy of forest thinning to mitigate drought impacts in mountain forests in the European Alps. Ecol Appl 25(4):1083-1098. https://doi.org/10.1890/14-0690.1

Etzold S, Ziemińska K, Rohner B, Bottero A, Bose AK, Ruehr NK, Zingg A, Rigling A (2019) One century of forest monitoring data in Switzerland reveals species- and site-specific trends of climateinduced tree mortality. In Frontiers in plant science 10:307. https:// doi.org/10.3389/fpls.2019.00307

Fontes L, Bontemps J-D, Bugmann H, van Oijen M, Gracia C, Kramer K et al (2010) Models for supporting forest management in a changing environment. In Forest Systems 19:8-29

Forrester DI, Albrecht AT (2014) Light absorption and light-use efficiency in mixtures of Abies alba and Picea abies along a productivity gradient. In Forest Ecology and Management 328:94-102. https:// doi.org/10.1016/j.foreco.2014.05.026

Forrester DI, Bauhus J (2016) A review of processes behind diversityproductivity relationships in forests. Curr Forestry Rep 2(1):45-61. https://doi.org/10.1007/s40725-016-0031-2

Forrester DI, Kohnle U, Albrecht AT, Bauhus J (2013) Complementarity in mixed-species stands of Abies alba and Picea abies varies with climate, site quality and stand density. In Forest Ecology and Management 304:233-242. https://doi.org/10.1016/j.foreco.2013. 04.038

Gazol A, Camarero JJ, Anderegg WRL, Vicente-Serrano SM (2017) Impacts of droughts on the growth resilience of Northern Hemisphere forests. In Global Ecol. Biogeogr. 26(2):166-176. https://doi.org/10.1111/geb.12526

Gleason KE, Bradford JB, Bottero A, D'Amato AW, Fraver S, Palik BJ, Battaglia MA, Iverson L, Kenefic L, Kern CC (2017) Competition amplifies drought stress in forests across broad climatic and compositional gradients. In Ecosphere 8(7):e01849. https://doi.org/10. 1002/ecs2.1849

Grassi G, Umberto Bagnaressi U (2001) Foliar morphological and physiological plasticity in Picea abies and Abies alba saplings along a natural light gradient. In Tree physiology 21:959-967

Greve P, Gudmundsson L, Seneviratne SI (2018) Regional scaling of annual mean precipitation and water availability with global temperature change. In Earth Syst. Dynam. 9(1):227-240. https://doi.org/ 10.5194/esd-9-227-2018

Grossiord C, Granier A, Ratcliffe S, Bouriaud O, Bruelheide H, Chećko E et al (2014) Tree diversity does not always improve resistance of forest ecosystems to drought. Proc Natl Acad Sci U S A 111(41): 14812-14815. https://doi.org/10.1073/pnas.1411970111

Guillemot J, Francois C, Hmimina G, Dufrêne E, Martin-StPaul NK, Soudani K, Marie G, Ourcival J-M, Delpierre N (2017) Environmental control of carbon allocation matters for modelling forest growth. The New phytologist 214(1):180-193. https://doi. org $/ 10.1111 /$ nph. 14320

Gutiérrez AG, Snell RS, Bugmann H (2016) Using a dynamic forest model to predict tree species distributions. Glob Ecol Biogeogr 25(3):347-358. https://doi.org/10.1111/geb.12421 
Hoegh-Guldberg O, Jacob D, Taylor M, Bindi M, Brown S, Camilloni I, Diedhiou A, Djalante R, Ebi KL, Engelbrecht F, Guiot J, Hijioka Y, Mehrotra S, Payne A, Seneviratne SI, Thomas A, Warren R, Zhou G (2018) Impacts of $1.5^{\circ} \mathrm{C}$ global warming on natural and human systems. In: Masson-Delmotte V, Zhai P, Pörtner H-O, Roberts D, Skea J, Shukla PR, Pirani A, Moufouma-Okia W, Péan C, Pidcock $\mathrm{R}$ (eds) Global Warming of $1.5^{\circ} \mathrm{C}$. An IPCC Special Report on the impacts of global warming of $1.5^{\circ} \mathrm{C}$ above pre-industrial levels and related global greenhouse gas emission pathways, in the context of strengthening the global response to the threat of climate change, sustainable development, and efforts to eradicate poverty

Huber N, Bugmann H, Lafond V (2018) Global sensitivity analysis of a dynamic vegetation model. Model sensitivity depends on successional time, climate and competitive interactions. In Ecological Modelling 368:377-390. https://doi.org/10.1016/j.ecolmodel.2017. 12.013

Huber N, Bugmann H, Lafond V (2020) Capturing ecological processes in dynamic forest models. Why there is no silver bullet to cope with complexity. In Ecosphere 11(5):1. https://doi.org/10.1002/ecs2. 3109

Ingrisch J, Bahn M (2018) Towards a comparable quantification of resilience. Trends Ecol Evol 33(4):251-259. https://doi.org/10.1016/j. tree.2018.01.013

Jones TA, Domke GM, Thomas SC (2009) Canopy tree growth responses following selection harvest in seven species varying in shade tolerance. In Can J For Res 39(2):430-440. https://doi.org/ 10.1139/X08-186

Jones SM, Bottero A, Kastendick DN, Palik BJ (2019) Managing red pine stand structure to mitigate drought impacts. In Dendrochronologia 57:125623. https://doi.org/10.1016/j.dendro. 2019.125623

Knoke T, Moog M, Plusczyk N (2001) On the effect of volatile stumpage prices on the economic attractiveness of a silvicultural transformation strategy. In Forest Policy and Economics 2:229-240

Knoke T, Paul C, Gosling E, Jarisch I, Mohr J, Seidl R (2021) Assessing the economic resilience of different management systems to severe forest disturbance. Available online at SSRN: https://ssrn.com/ abstract=3844645, https://doi.org/10.2139/ssrn.3844645

Kölling C (2007) Klimahüllen für 27 Waldbaumarten. AFZ-DerWald 23: $1242-1245$

Landsberg J, Sands P (2011) Physiological ecology of forest production. Principles, processes and models. 1st ed. Elsevier Inc, San Diego, California, USA

Lévesque M, Saurer M, Siegwolf R, Eilmann B, Brang P, Bugmann H, Rigling A (2013) Drought response of five conifer species under contrasting water availability suggests high vulnerability of Norway spruce and European larch. Glob Chang Biol 19(10): 3184-3199. https://doi.org/10.1111/gcb.12268

Lindner M, Maroschek M, Netherer S, Kremer A, Barbati A, GarciaGonzalo J, Seidl R, Delzon S, Corona P, Kolström M, Lexer MJ, Marchetti M (2010) Climate change impacts, adaptive capacity, and vulnerability of European forest ecosystems. For Ecol Manag 259(4):698-709. https://doi.org/10.1016/j.foreco.2009.09.023

Lloret F, Keeling EG, Sala A (2011) Components of tree resilience. Effects of successive low-growth episodes in old ponderosa pine forests. In Oikos 120(12):1909-1920. https://doi.org/10.1111/j. 1600-0706.2011.19372.x

Mäkelä A, Landsberg J, Ek AR, Burk TE, Ter-Mikaelian M, Agren GI et al (2000) Process-based models for ecosystem management: current state of the art and challenges for practical implementation. In Tree physiology 20:289-298

Martínez-Vilalta J, Garcia-Forner N (2017) Water potential regulation, stomatal behaviour and hydraulic transport under drought. Deconstructing the iso/anisohydric concept. In Plant, cell \& environment 40(6):962-976. https://doi.org/10.1111/pce.12846
Messerer K, Kacprowski T, Kolo H, Baumbach J, Knoke T (2020) Importance of considering the growth response after partial harvesting and economic risk of discounted net revenues when optimizing uneven-aged forest management. In Can J For Res 50(5):487-499. https://doi.org/10.1139/cjfr-2018-0546

Mina M, Bugmann H, Cordonnier T, Irauschek F, Klopcic M, Pardos M, Cailleret M (2017a) Future ecosystem services from European mountain forests under climate change. J Appl Ecol 54(2):389 401. https://doi.org/10.1111/1365-2664.12772

Mina M, Bugmann H, Klopcic M, Cailleret M (2017b) Accurate modeling of harvesting is key for projecting future forest dynamics. A case study in the Slovenian mountains. In Reg Environ Change 17(1): 49-64. https://doi.org/10.1007/s10113-015-0902-2

Moore AD (1989) On the maximum growth equation used in forest gap simulation models. In Ecological Modelling 45:63-67

Neumann M, Mues V, Moreno A, Hasenauer H, Seidl R (2017) Climate variability drives recent tree mortality in Europe. Glob Chang Biol 23(11):4788-4797. https://doi.org/10.1111/gcb.13724

Niinemets Ü, Valladares F (2006) Tolerance to shade, drought, and waterlogging of temperate Northern hemisphere trees and shrubs. Ecol Monogr 76(4):521-547

Niinimäki S, Tahvonen O, Mäkelä A (2012) Applying a process-based model in Norway spruce management. In Forest Ecology and Management 265:102-115. https://doi.org/10.1016/j.foreco.2011. 10.023

Nikinmaa L, Lindner M, Cantarello E, Jump AS, Seidl R, Winkel G, Muys B (2020) Reviewing the use of resilience concepts in forest sciences. Curr Forestry Rep 6(2):61-80. https://doi.org/10.1007/ s40725-020-00110-x

Olson ME, Soriano D, Rosell JA, Anfodillo T, Donoghue MJ, Edwards EJ, León-Gómez C, Dawson T, Camarero Martínez JJ, Castorena M, Echeverría A, Espinosa CI, Fajardo A, Gazol A, Isnard S, Lima RS, Marcati CR, Méndez-Alonzo R (2018) Plant height and hydraulic vulnerability to drought and cold. Proc Natl Acad Sci U S A 115(29):7551-7556. https://doi.org/10.1073/pnas.1721728115

Pardos M, del Río M, Pretzsch H, Jactel H, Bielak K, Bravo F, Brazaitis G, Defossez E, Engel M, Godvod K, Jacobs K, Jansone L, Jansons A, Morin X, Nothdurft A, Oreti L, Ponette Q, Pach M, Riofrío J, Ruíz-Peinado R, Tomao A, Uhl E, Calama R (2021) The greater resilience of mixed forests to drought mainly depends on their composition. Analysis along a climate gradient across Europe. For Ecol Manag 481(7724):118687. https://doi.org/10.1016/j.foreco.2020. 118687

Pretzsch H (2020) Density and growth of forest stands revisited. Effect of the temporal scale of observation, site quality, and thinning. For Ecol Manag 460:117879. https://doi.org/10.1016/j.foreco.2020. 117879

Puettmann KJ, D'Amato AW, Kohnle U, Bauhus J (2009) Individual-tree growth dynamics of mature Abies alba during repeated irregular group shelterwood (Femelschlag) cuttings. In Can J For Res 39(12):2437-2449. https://doi.org/10.1139/X09-158

Pukkala T (2021) Measuring the social performance of forest management. In J For Res. https://doi.org/10.1007/s11676-021-01321-z

Radke N, Keller K, Yousefpour R, Hanewinkel M (2020) Identifying decision-relevant uncertainties for dynamic adaptive forest management under climate change. Clim Chang 163(2):891-911. https:// doi.org/10.1007/s10584-020-02905-0

Rasche L, Fahse L, Zingg A, Bugmann H (2011) Getting a virtual forester fit for the challenge of climatic change. J Appl Ecol 48(5):1174 1186. https://doi.org/10.1111/j.1365-2664.2011.02014.x

Rasche L, Fahse L, Zingg A, Bugmann H (2012) Enhancing gap model accuracy by modeling dynamic height growth and dynamic maximum tree height. In Ecological Modelling 232:133-143. https://doi. org/10.1016/j.ecolmodel.2012.03.004

Schwarz J, Skiadaresis G, Kohler M, Kunz J, Schnabel F, Vitali V, Bauhus J (2020) Quantifying growth responses of trees to 
drought - a critique of commonly used resilience indices and recommendations for future studies. Curr Forestry Rep 6(3):185-200. https://doi.org/10.1007/s40725-020-00119-2

Seidl R, Vigl F, Rössler G, Neumann M, Rammer W (2017) Assessing the resilience of Norway spruce forests through a model-based reanalysis of thinning trials. In Forest Ecology and Management 388: 3-12. https://doi.org/10.1016/j.foreco.2016.11.030

Senf C, Pflugmacher D, Zhiqiang Y, Sebald J, Knorn J, Neumann M et al (2018) Canopy mortality has doubled in Europe's temperate forests over the last three decades. Nat Commun 9(1):4978. https://doi.org/ 10.1038/s41467-018-07539-6

Sidor CG, Popa I, Vlad R, Cherubini P (2015) Different tree-ring responses of Norway spruce to air temperature across an altitudinal gradient in the Eastern Carpathians (Romania). Trees 29(4):985997. https://doi.org/10.1007/s00468-015-1178-3

Sohn JA, Hartig F, Kohler M, Huss J, Bauhus J (2016a) Heavy and frequent thinning promotes drought adaptation in Pinus sylvestris forests. Ecol Appl 26(7):2190-2205

Sohn JA, Saha S, Bauhus J (2016b) Potential of forest thinning to mitigate drought stress. A meta-analysis. In Forest Ecology and Management 380:261-273. https://doi.org/10.1016/j.foreco.2016.07.046

Stovall AEL, Shugart H, Yang X (2019) Tree height explains mortality risk during an intense drought. Nat Commun 10(1):4385. https://doi. org/10.1038/s41467-019-12380-6

Stuart-Haëntjens E, de Boeck HJ, Lemoine NP, Mänd P, Kröel-Dulay G, Schmidt IK et al (2018) Mean annual precipitation predicts primary production resistance and resilience to extreme drought. In The Science of the total environment 636:360-366. https://doi.org/10. 1016/j.scitotenv.2018.04.290

Temperli C, Bugmann H, Elkin C (2013) Cross-scale interactions among bark beetles, climate change, and wind disturbances: a landscape mdeling approach. Ecol Monogr 83(3):383-402

Thrippleton T, Lüscher F, Bugmann H (2020) Climate change impacts across a large forest enterprise in the Northern Pre-Alps. Dynamic forest modelling as a tool for decision support. In Eur J Forest Res 139(3):483-498. https://doi.org/10.1007/s10342-020-01263-x

Weise U (1996) Zuwachsreaktion auf Bestandeslichtung in Fi-Ta(Bu)Naturverjüngungsbeständen. Agrarforschung in BadenWürttemberg. Vol. 26. Forstliche Versuchs- und Forschungsanstalt Baden-Württemberg, Freiburg, Germany, pp 271-280

Yousefpour R, Jacobsen JB, Thorsen BJ, Meilby H, Hanewinkel M, Oehler K (2012) A review of decision-making approaches to handle uncertainty and risk in adaptive forest management under climate change. Ann For Sci 69(1):1-15. https://doi.org/10.1007/s13595011-0153-4

Yousefpour R, Augustynczik ALD, Hanewinkel M (2017) Pertinence of reactive, active, and robust adaptation strategies in forest management under climate change. Ann For Sci 74(2):660. https://doi.org/ 10.1007/s13595-017-0640-3

Yousefpour R, Augustynczik ALD, Reyer CPO, Lasch-Born P, Suckow F, Hanewinkel M (2018) Realizing mitigation efficiency of European commercial forests by climate smart forestry. Sci Rep 8(1):345. https://doi.org/10.1038/s41598-017-18778-w

Yousefpour R, Nabel JEMS, Pongratz J (2019) Simulating growth-based harvest adaptive to future climate change. Biogeosciences 16(2): 241-254. https://doi.org/10.5194/bg-16-241-2019

Zang C, Hartl-Meier C, Dittmar C, Rothe A, Menzel A (2014) Patterns of drought tolerance in major European temperate forest trees. Climatic drivers and levels of variability. In Global change biology 20(12): 3767-3779. https://doi.org/10.1111/gcb.12637

Zou CB, Barron-Gafford GA, Breshears DD (2007) Effects of topography and woody plant canopy cover on near-ground solar radiation. Relevant energy inputs for ecohydrology and hydropedology. Geophys Res Lett 34(24):1984. https://doi.org/10.1029/ 2007GL031484

Publisher's note Springer Nature remains neutral with regard to jurisdictional claims in published maps and institutional affiliations.

\section{Affiliations}

\section{Juan Carlos Zamora-Pereira ${ }^{1}$ (D) $\cdot$ Rasoul Yousefpour $^{1}$ (D) $\cdot$ Maxime Cailleret $^{2,3,4}$ (D) $\cdot$ Harald Bugmann $^{3}$ (D) Marc Hanewinkel ${ }^{1}$ (ID}

1 Chair of Forestry Economics and Forest Planning, University of Freiburg, Tennenbacherstr. 4, 79106 Freiburg, Germany
3 Forest Ecology, Institute of Terrestrial Ecosystems, Department of Environmental Systems Science, ETH Zürich, Zürich, Switzerland

4 Swiss Federal Institute for Forest, Snow and Landscape Research (W.S.L.), Birmensdorf, Switzerland 